\title{
Vascular Endothelial Cells Produce Coagulation Factors That Control Their Growth via Joint Protease-Activated Receptor and C5a Receptor 1 (CD88) Signaling
}

Devin Cao, ${ }^{*}$ Michael G. Strainic, ${ }^{*}$ Daniel Counihan, ${ }^{*}$ Shiva Sridar, ${ }^{*}$ Fengqi An, ${ }^{*}$ Wasim Hussain, ${ }^{*}$ Alvin H. Schmaier, Marvin Nieman, ${ }^{\ddagger}$ and M. Edward Medof*

From the Institute of Pathology* and the Department of Pharmacology, ${ }^{\ddagger}$ Case Western Reserve University, Cleveland; and the Department of Medicine, ${ }^{\dagger}$ University Hospitals Cleveland Medical Center, Cleveland, Ohio

Accepted for publication September 29, 2021.

Address correspondence to M. Edward Medof, M.D., Ph.D., Institute of Pathology, 2085 Adelbert, Room 301, Cleveland, OH 44106. E-mail: mxm16@case.edu.

\begin{abstract}
As per the classical view of the coagulation system, it functions solely in plasma to maintain hemostasis. An experimental approach modeling vascular reconstitution was used to show that vascular endothelial cells (ECS) endogenously synthesize coagulation factors during angiogenesis. Intracellular thrombin generated from this synthesis promotes the mitotic function of vascular endothelial cell growth factor $A$ (VEGF-A). The thrombin concurrently cleaves C5a from EC-synthesized complement component C5 and unmasks the tethered ligand for EC-expressed protease-activated receptor 4 (PAR4). The two ligands jointly trigger EC C5a receptor-1 (C5ar1) and PAR4 signaling, which together promote VEGF receptor 2 growth signaling. C5ar1 is functionally associated with PAR4, enabling C5a or thrombin to elicit Gai and/ or Gaq signaling. EC coagulation factor and EC complement component synthesis concurrently downregulate with contact inhibition. The connection of these processes with VEGF receptor 2 signaling provides new insights into mechanisms underlying angiogenesis. Knowledge of endogenous coagulation factor/complement component synthesis and joint PAR4/C5ar1 signaling could be applied to other cell types. (Am J Pathol 2022, 192: 361-378; https://doi.org/10.1016/j.ajpath.2021.09.011)
\end{abstract}

The complement and coagulation systems have been envisioned as residing exclusively in the plasma, deriving solely from the liver, and functioning independently of each other in innate immunity and in hemostasis, respectively. Because of this, although effects of complement activation fragments on the coagulation cascade and vice versa have been reported, they have been attributed to cross talk and regarded as being modulatory rather than integral to one pathway or the other. ${ }^{1}$ For example, although the immediate response to trauma includes both proteolysis of fibrinogen to form fibrin and complement activation, the two processes have been regarded as being unconnected and serving unrelated purposes.

Both coagulation and complement system products exert effects on vascular endothelial cells (ECs). Thrombin is connected to EC tissue factor production and procoagulant surface protein expression during coagulation. ${ }^{2-5}$ Complement activation fragments $\mathrm{C} 3 \mathrm{a}$ and $\mathrm{C} 5 \mathrm{a}$ are linked to $\mathrm{EC}$ integrin expression and proinflammatory cytokine production during inflammation. ${ }^{5}$ Thrombin confers its modulatory effects on ECs via protease-activated receptors (PARs). Its cleavage of the $\mathrm{N}$-termini of these G-protein-coupled receptors (GPCRs) unmasks their tethered ligands, thereby inducing their signaling. Four PAR family members (PAR1 to PAR4) exist, and PAR1 and PAR4, which frequently function cooperatively, are expressed on ECs. ${ }^{2,3,6,7}$ In addition to their expression on ECs, PARs are widely expressed on other cell types and implicated in

Supported by NIH R01 HL109561 (M.E.M.), R01 AR067182 (M.E.M.), R01 HL052779 (A.H.S.), HL126634 (A.H.S.), R01 HL098217 (M.N.), and EY11373 (Ophthalmology Core; Principal Investigator: Irina Pikuleva).

D.Ca., M.G.S., and D.Co. contributed equally to this work.

Disclosures: None declared. 
many cell functions. ${ }^{5}$ Although C5a receptor-1 (C5ar1) was long thought to be strictly limited to myeloid phagocytic cells, ${ }^{8-10}$ it now is known to function in adaptive immune cells ${ }^{11-14}$ as well as other cell types. ${ }^{15}$ Recent studies ${ }^{16}$ have shown that EC C5 synthesis and C5a production are interconnected with vascular endothelial cell growth factor A (VEGF-A) function. Thrombin, however, has been regarded as functioning solely in the context of coagulation in plasma.

Thrombin is generated from prothrombin in a complex termed prothrombinase that is produced by factor $\mathrm{Va}$ binding to factor Xa and factor II (FII) on the EC surface. Factor Xa generation, leading to the assembly of prothrombinase, is induced by the actions of factor IXa and factor VIIIa or factor VIIa and tissue factor. These processes are tightly regulated by homeostasis. The same is true for assembly of the canonical C5 convertases $(\mathrm{C} 4 \mathrm{~b} 2 \mathrm{a} 3 \mathrm{~b}$ and $\mathrm{C} 3 \mathrm{bBbC} 3 \mathrm{~b}$ ) that gives rise to $\mathrm{C} 5 \mathrm{a}$. $\mathrm{A}$ previous study ${ }^{17}$ linked plasma $\mathrm{C} 5$ a generation with thrombin in a mouse model of immune complex-mediated lung injury. Although thrombin cleaved purified complement component $\mathrm{C} 5$ to $\mathrm{C} 5 \mathrm{a}$ in vitro, the authors proposed that the process constituted a compensatory mechanism for C5 cleavage connected with increased thrombin generation in plasma during disease. A role for this process in a nonhemostatic physiological process was not proposed.

C5a was recently linked with physiological VEGF-A growth induction. However, based on prior immune cell activation studies, it was theorized to be generated by the conventional alternative pathway $\mathrm{C} 5$ convertase $\mathrm{C} 3 \mathrm{bBbC} 3 \mathrm{~b}$. These studies demonstrated that interacting dendritic cell $-\mathrm{CD} 4^{+}$cell partners each generate $\mathrm{C} 5 \mathrm{a}$ (and $\mathrm{C} 3 \mathrm{a}$ ) from complement components that are endogenously synthesized by both cell types, ${ }^{12,14}$ and that the GPCR signaling plays an integral role in shaping the Tcell response. Analogous to the findings in immune cells, the studies of C5a production by ECs showed that autocrine C5ar1 signaling plays a requisite role in vascular endothelial cell growth factor receptor 2 (VEGFR2) mitotic signaling. It promotes VEGFR2 autophosphorylation, downstream growth signaling via the canonical VEGFR2 cascades, and EC transition through the cell cycle.

The findings of local complement production in $\mathrm{ECs}^{16}$ together with the observation ${ }^{17}$ that thrombin can cleave C5a from C5 in vitro prompted the hypothesis that ECs might endogenously produce coagulation factors in addition to complement components, and that EC produced thrombin might participate in EC C5a generation. Therefore, this study investigated whether endogenous thrombin generation, if locally produced within ECs, might be mechanistically linked with endogenous C5a generation in ECs, and whether these linkages might participate in EC proliferation and angiogenesis.

\section{Materials and Methods}

\section{Cells, Antibodies, and Reagents}

The sources of cells and major reagents used in each assay are given with each assay method. All cells and reagents used are listed together in detail in the major resource table (Table 1).

\section{Growth Assays and Real-Time Quantitative PCR}

Murine bEnd 3 and NIH-3T3 cell lines were maintained in Dulbecco's modified Eagle's medium containing 10\% fetal bovine serum. Human umbilical vein endothelial cells (HUVECs) and human aortic endothelial cells (HAECs) were maintained in EBM-2 media containing BulletKit (Lonza, Basel, Switzerland) without added vitamin K. Except where indicated, cells were seeded at $2.5 \times 10^{4}$ per well in 24-well plates in complete media, after which they were transferred to media containing $0.5 \%$ serum and treated as described in the figure legends. The concentrations of C5a, C5ar1-A, ${ }^{12,14,16,18}$ thrombin, ${ }^{19-21}$ and PAR1 and PAR4 agonists and antagonists ${ }^{22,23}$ were chosen on the basis of previous studies and the manufacturer's directions. Cell numbers were counted manually. Real-time quantitative PCR was performed as described. ${ }^{12}$ Data are given as fold increases relative to basal levels corrected for actin or glyceraldehyde-3-phosphate dehydrogenase.

\section{Coagulation Assays}

A total of $100 \mu \mathrm{L}$ of culture supernatant was incubated at $37^{\circ} \mathrm{C}$ for 5 minutes with $100 \mu \mathrm{L}$ of plasma deficient in FII, factor V (FV), factor VII (FVII), or factor X (FX; George King Biomedical, Overland Park, KS). A total of $100 \mu \mathrm{L}$ of Phospoplastin RL (R2 Diagnostics, South Bend, IN) was then added, and time to coagulation was measured while continuously mixing. Percentage clotting activity corresponds to the dilution of pooled human plasma (George King Biomedical), yielding the same clotting time.

\section{Enzyme-Linked Immunosorbent Assays and Flow Cytometry}

Enzyme-linked immunosorbent assays for C5a and flow cytometry for phosphorylated STAT3 were performed as described. ${ }^{12}$ Intracellular staining was performed following permeabilization, as in past studies, ${ }^{24}$ and the intracellular signal was calculated following subtraction of the extracellular signal.

\section{GSK-3 $\beta$ Assay}

The assay was performed using the glycogen synthase kinase (GSK)-3 $\beta$ Activity Assay kit (Sigma-Aldrich, St. Louis, MO; catalog number CS0990), per the manufacturer's protocol.

\section{Sprouting Assay}

Thoracic aortae were obtained from 8- to 14-week-old mice following perfusion with Ringer's solution. Following 
removal of fibroadipose tissue, approximately 1-mm segments were suspended in a 6-mm petri dish containing complete EGM-2 (Lonza) with reduced growth factor Matrigel (Corning, Tewskbury, MA). Aortic ring sprouts were imaged on days 6 to 8 , and sprout areas were determined by morphometric analysis using MetaMorph (Molecular Devices, San Jose, CA) and a Leica DMI6000 microscope (Wetzlar, Germany).

\section{Matrigel Plug Angiogenesis Assay}

Reduced growth factor Matrigel (as used in sprouting assays; $500 \mu \mathrm{L})$ supplemented with heparin $(60 \mathrm{U} / \mathrm{mL})$ and VEGF-A (300 ng/mL) was injected subcutaneously into the lower abdominal flank of anesthetized 8- to 14-week-old wild-type (WT) C57BL/6 mice. Ten days after injection, recovered Matrigel plugs were fixed in formalin, embedded in OCT compound, and sectioned. Sections were stained for different coagulation factors [anti-FII (Aviva Systems Biology Corp., San Diego, CA; ARP41757-P050; lot number QC12431), anti-FV (Bioss, Woburn, MA; bs-1040R; lot number AD121701), anti-FVII (Bioss; bs-4846R; lot number YE1022W), or anti-FX (Bioss; bs-9501R; lot number 9B26M7)] followed by AF546-labeled anti-rabbit. After coagulation protein staining, cells were counterstained with AF488-labeled anti-CD31 (clone 390; BD Biosciences, East Rutherford, NJ), mounted in ProLong Gold anitfade reagent with DAPI (Molecular Probes, Eugene, OR; catalog number P36935), and visualized by confocal microscopy. Images were collected using a $63 \times(1.4$ numerical aperture) oil immersion objective on a Leica HyVolution SP8 inverted confocal microscope. Resulting images were subjected to deconvolution using Hyugens Professional (Hilversum, The Netherlands).

\section{Confocal Microscopy}

For C5ar1 and PAR4 colocalization assays, bEnd.3 cells were grown overnight on ibiTreat 8 chamber $\mu$-Slides (ibidi, Martinsried, Germany). The slides were washed three times with $1 \times$ phosphate-buffered saline and fixed with $2 \%$ formaldehyde. Cells were stained with a cocktail containing $2 \mu \mathrm{g} / \mathrm{mL}$ of each of anti-C5ar1-AF488 (Abd Serotec, Oxford, UK) and anti-Par4-AF546 (Abcam, Cambridge, UK) for 1 hour. For Matrigel plug assays, plugs were implanted into the inner thighs of WT mice for 10 days. Plugs were harvested, embedded in OCT compound, and sectioned. Sections were stained with anti-FII, anti-FV, antiFVII, or anti-FX, followed by AF546-labeled anti-rabbit secondary antibody (Ab). Cells were counterstained with anti-CD31 (green). Nuclei were visualized with DAPI (blue). For coagulation factor staining in confluent versus nonconfluent cells, HUVECs were grown to $70 \%$ and $100 \%$ confluence, fixed with $2 \%$ formaldehyde, and blocked with $5 \%$ horse serum in phosphate-buffered saline. Cells were stained with anti-FII followed by AF546-labeled anti-rabbit secondary Ab.
All images were collected using a $63 \times(1.4$ numerical aperture) oil immersion objective on a Leica HyVolution SP8 inverted confocal microscope. Resulting images were subjected to deconvolution using Hyugens Professional.

\section{Co-Immunoprecipitation Assays}

Cells were lysed in $1 \times$ Cell Lysis Buffer $(10 \times$; Cell Signaling, Danvers, MA); catalog number 9803) supplemented with 1 $\mathrm{mmol} / \mathrm{L}$ phenylmethylsulfonyl fluoride and 1 Complete Mini protease inhibitor tablet (Roche, Boston, MA; catalog number $11836153001)$ for 10 minutes on ice $(1 \mathrm{mmol} / \mathrm{L} \mathrm{Na}$ orthovanadate was used to inhibit phosphatase activity when lysates were to be assayed for kinase activity). Lysates were then sonicated three times for 2 minutes to break apart nucleic acids, after which the cells were centrifuged for 10 minutes at 12,000 $\times g$. Clean supernatants were transferred to new tubes and incubated with Protein-A/G beads (Santa Cruz Biotechnology, Dallas, TX) to preclear the lysates and prevent nonspecific coimmunoprecipitation. Abs against PAR4, C5ar1, GSK- $\beta$, and CD59 were added, and samples were incubated overnight at $4^{\circ} \mathrm{C}$. Protein-A/G beads were used to pull down $\mathrm{Ab}$, and immunoprecipitations were assayed by Western blot analysis, enzyme-linked immunosorbent assay, or protein activity via kits, as described.

\section{BRET Data}

Bioluminescence resonance energy transfer (BRET) analyses were performed as described. ${ }^{25}$ Briefly, HEK293 cells $\left(1 \times 10^{5}\right)$ were transfected with $0.5 \mu \mathrm{g}$ of Par4-Luc donor plasmid and increasing amounts ( 0 to $5 \mu \mathrm{g}$ ) of C5arl-green fluorescent protein (GFP) acceptor plasmid or C5arl-Luc donor plasmid and increasing amounts $(0$ to $5 \mu \mathrm{g}$ ) of C5arl-GFP or Par4-GFP acceptor plasmids. Emission was detected using a PerkinElmer Life Sciences (Waltham, MA) Victor 3 plate reader equipped with the appropriate BRET2 filter set (410 nm with 80-nm bandpass and $515 \mathrm{~nm}$ with 30$\mathrm{nm}$ bandpass; PerkinElmer Life Sciences). Emission at 410 and $515 \mathrm{~nm}$ was collected immediately after the addition of 5 $\mu \mathrm{mol} / \mathrm{L}$ luciferase substrate (coelenterazine 400a; Biotium Inc., Hayward, CA). BRET signal was calculated by the ratio of emission at $515 \mathrm{~nm}$ to emission at $410 \mathrm{~nm}$ minus the BRET in the absence of GFP. In BRET studies, specific interactions are detected by a hyperbolic increase in the BRET signal (ratio of emission at 510/410 nm) as the ratio of GFPreceptor/RLuc-receptor increased, whereas nonspecific interactions increased linearly. Data were analyzed with Prism 6 (GraphPad, San Diego, CA) using best model (hyperbolic versus linear) for each experiment. GFP expression was determined by excitation at $495 \mathrm{~nm}$ and emission at $515 \mathrm{~nm}$. Luciferase expression was determined by adding $5 \mu \mathrm{m}$ coelenterazine $\mathrm{H}$ (Invitrogen, Carlsbad, CA) and reading total light emission without a filter. Each BRET assay was performed in three independent experiments. 
Table 1 Major Resources

Animals (in vivo studies)

\begin{tabular}{|c|c|c|c|}
\hline Species & Vendor or source & $\begin{array}{l}\text { Background } \\
\text { strain }\end{array}$ & Sex \\
\hline Mouse & Jackson Laboratories, Bar Harbor, ME & C57BL/6 & $M / F$ \\
\hline Mouse & C. Gerard, Children's Hospital, Boston, MA & $\mathrm{C} 57 \mathrm{BL} / 6, \mathrm{C} \mathrm{ar1}^{-/-}$ & $M / F$ \\
\hline Mouse & Jackson Laboratories & $P A R 1^{-/-}$ & $M / F$ \\
\hline Mouse & $\begin{array}{l}\text { Mutant Mouse Resource \& Research } \\
\text { Centers, University of California, Davis, } \\
\text { CA }\end{array}$ & $P A R 3^{-/-}$PAR4 $4^{-/-}$ & $\mathrm{M} / \mathrm{F}$ \\
\hline
\end{tabular}

Animal breeding

\begin{tabular}{|c|c|c|c|c|}
\hline Parent & Species & Vendor or source & Background strain & $\begin{array}{l}\text { Other } \\
\text { information }\end{array}$ \\
\hline M & Mouse & Jackson Laboratories & $\mathrm{C} 57 \mathrm{BL} / 6$ & \\
\hline M & Mouse & C. Gerard & $\mathrm{BALB} / \mathrm{C}, \mathrm{C} \mathrm{arr}^{-/-}$ & $\begin{array}{c}\text { Crossbred for } 12 \\
\text { generations }\end{array}$ \\
\hline $\mathrm{F}$ & Mouse & C. Gerard & $\mathrm{C} 57 \mathrm{BL} / 6$ & $\begin{array}{c}\text { Crossbred for } 12 \\
\text { generations }\end{array}$ \\
\hline $\mathrm{F}$ & Mouse & C. Gerard & $\mathrm{C} 57 \mathrm{BL} / 6, \mathrm{C5ar1}^{-/-}$ & \\
\hline M & Mouse & $\begin{array}{l}\text { Mutant Mouse Resource \& } \\
\text { Research Centers }\end{array}$ & $\mathrm{C} 57 \mathrm{BL} / 6$, PAR1 $^{-/-}$ & \\
\hline $\mathrm{F}$ & Mouse & $\begin{array}{l}\text { Mutant Mouse Resource \& } \\
\text { Research Centers }\end{array}$ & $\mathrm{C} 57 \mathrm{BL} / 6, P A R 1^{-/-}$ & \\
\hline Antibodies & & & & \\
\hline
\end{tabular}

$\underline{\text { Antibodies }}$

\begin{tabular}{|c|c|c|c|c|}
\hline Target antigen & Vendor or source & Catalog no. & Working concentration & $\begin{array}{l}\text { (preferred but } \\
\text { not required) }\end{array}$ \\
\hline Human/mouse FII & $\begin{array}{l}\text { ThermoFisher, } \\
\text { Carlsbad, CA }\end{array}$ & PA1-43040 & $1 \mu \mathrm{mol} / \mathrm{mL}$ & SI2444095 \\
\hline Mouse FV & Bioss, Woburn, MA & Bs-1040R & $5 \mu \mathrm{g} / \mathrm{mL}$ & AD121701 \\
\hline Mouse FVII & Bioss & Bs-4846R & $5 \mu \mathrm{g} / \mathrm{mL}$ & YE1022W \\
\hline Mouse FX & Bioss & Bs-9501R & $5 \mu \mathrm{g} / \mathrm{mL}$ & 9B26M7 \\
\hline Human/mouse $\mathrm{C} 5 \mathrm{aR}$ & $\begin{array}{l}\text { Santa Cruz } \\
\text { Biotechnologies, } \\
\text { Dallas, TX }\end{array}$ & SC-53795 PE & $2 \mu \mathrm{g} / \mathrm{mL}$ & C1810 \\
\hline Mouse $\mathrm{C} 5 \mathrm{a}$ & $\begin{array}{l}\text { BD Biosciences, } \\
\text { Franklin Lakes, } \\
\text { NJ }\end{array}$ & 558027 & $5 \mu \mathrm{g} / \mathrm{mL}$ & \\
\hline Human C5a & $\begin{array}{l}\text { R\&D Systems, } \\
\text { Minneapolis, MN }\end{array}$ & AF2037 & $5 \mu \mathrm{g} / \mathrm{mL}$ & \\
\hline Human thrombin & ThermoFisher & HYB 109-04-02 & $5 \mu \mathrm{g} / \mathrm{mL}$ & UI2843443 \\
\hline Mouse/human PAR1 & BD Biosciences & 611522 & $5 \mu \mathrm{g} / \mathrm{mL}$ & 6013888 \\
\hline Mouse/human PAR4 & $\begin{array}{l}\text { Abcam, Cambridge, } \\
\text { UK }\end{array}$ & Ab5787 & $5 \mu \mathrm{g} / \mathrm{mL}$ & GR267332-5 \\
\hline $\begin{array}{l}\text { Human/mouse } \\
\text { VEGFR2 }\end{array}$ & $\begin{array}{l}\text { Cell Signalling } \\
\text { Technologies, } \\
\text { Danvers, MA }\end{array}$ & 2479 & $0.1 \mu \mathrm{g} / \mathrm{mL}$ & 18 \\
\hline
\end{tabular}


Lot no.

(preferred but

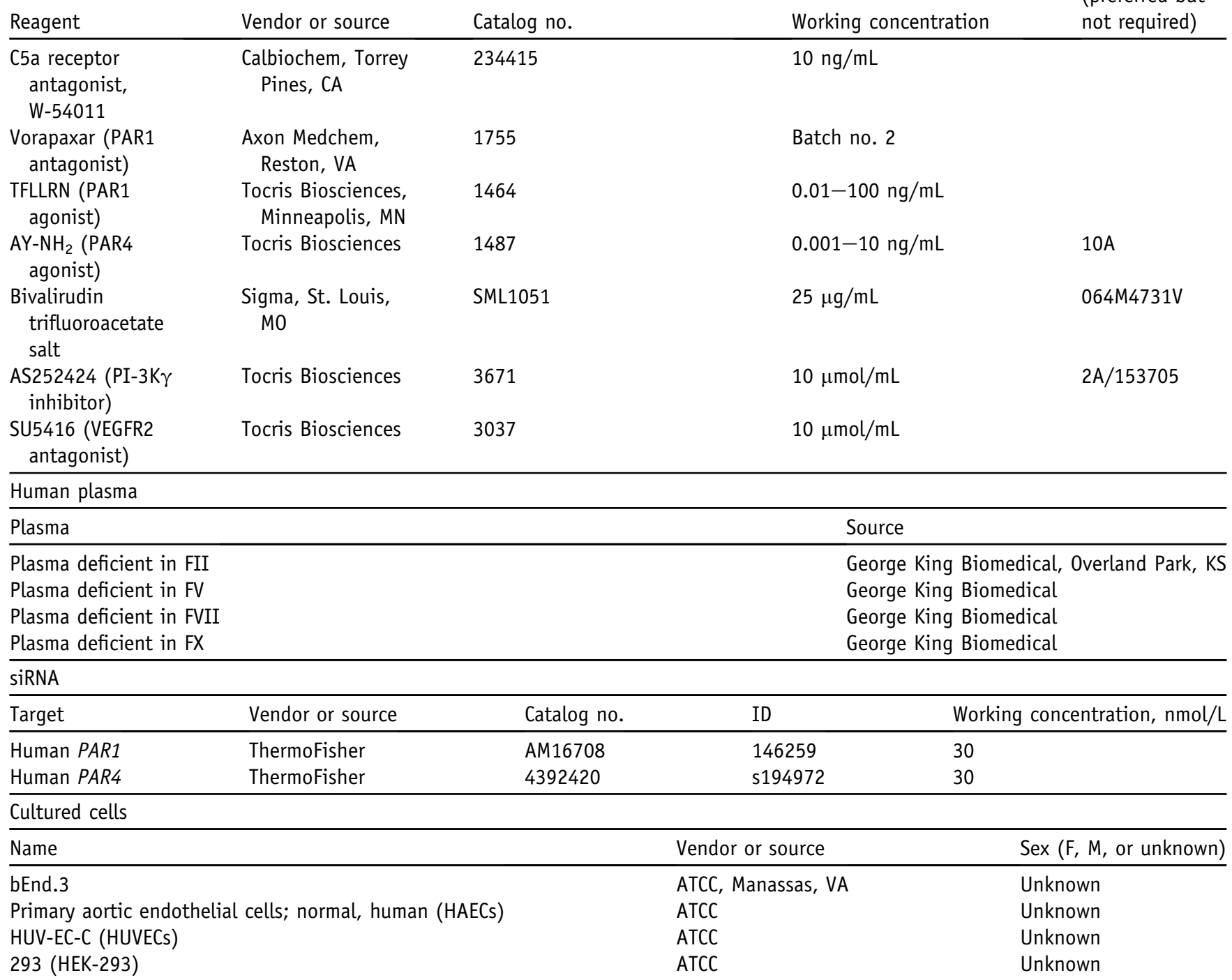

F, female; M, male; C5ar1, C5a receptor-1; FII, factor II; FV, factor V; FVII, factor VII; FX, factor X; HAEC, human aortic endothelial cell; HUVEC, human umbilical vein endothelial cell; ID, identifier; PAR, protease-activated receptor; VEGFR2, vascular endothelial cell growth factor receptor 2.

\section{RNA Interference}

siRNAs targeting human PARl (identifier: 146259) and PAR4 (identifier: s194972) were purchased from ThermoFisher (Carlsbad, CA). RNA interference was performed using Lipofectamine RNAiMAX Reagent (ThermoFisher) following the manufacturer's recommended protocol. Briefly, cells were treated with $30 \mathrm{nmol} / \mathrm{L}$ siRNA and transfection reagent at a 1:2 ratio under reduced serum conditions for 48 hours. Cells were returned to complete media, and knockdown was assessed using flow cytometry at 3 and 7 days. Silencer-Cy3 siRNA (ThermoFisher) was used as a nonspecific control.

\section{Statistical Analysis}

Power calculations and animal numbers were determined using the information provided by $h$ ttp://statpages.org and the therein linked Russ Lenth's power and sample-size calculator obtainable through http://www.stat.uiowa.edu/ rlenth/Power/index. html\#Download_to_run_locally (both last accessed September $12,2021)$. To achieve a true difference between means of 0.5 and a power of 0.2 testing the difference between two means via an unpaired, two-tailed $t$-test, 10 mice were required in each group and there were 10 experimental groups. Statistical significance for all experimental data was determined by $t$-test (unpaired, two tailed) performed in Microsoft Excel (Seattle, 
A

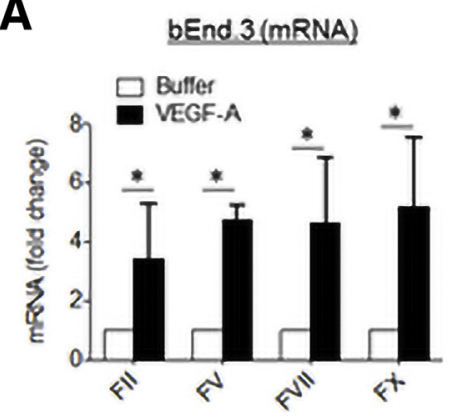

E

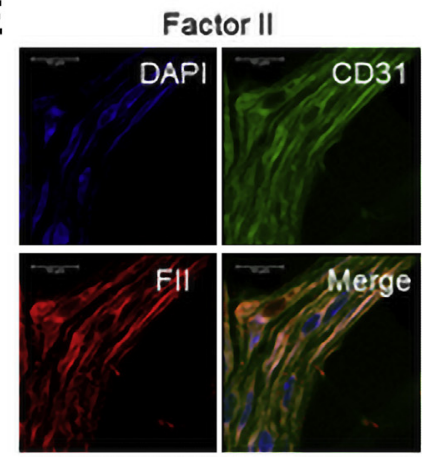

B

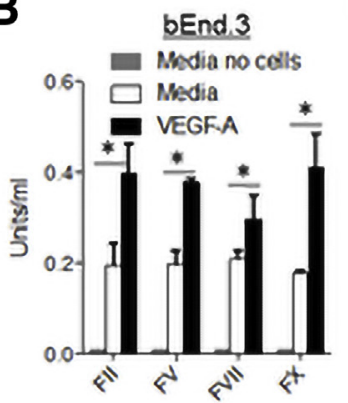

Factor V

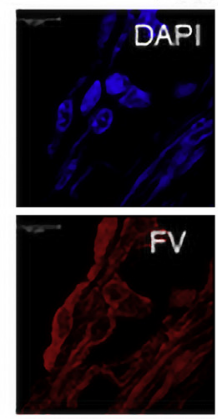

C

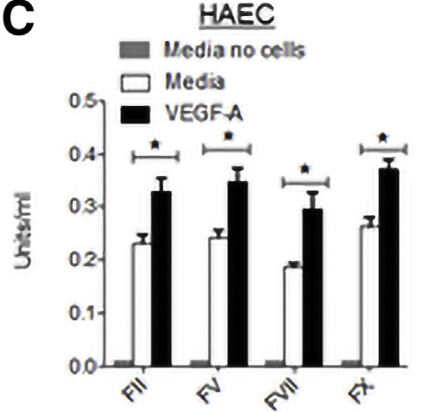

Factor VII

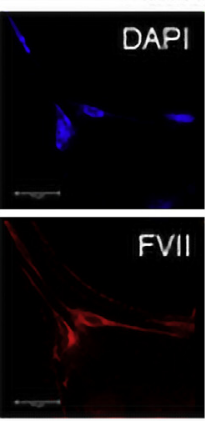

D

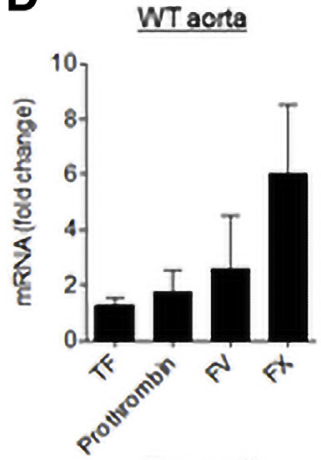

Factor $X$

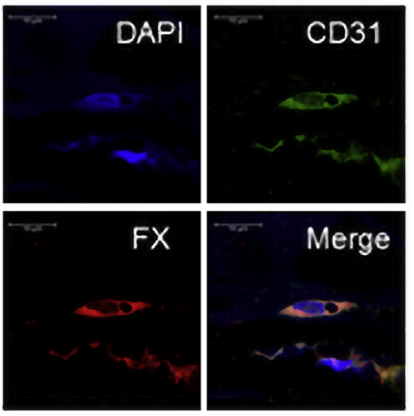

Figure 1 Vascular endothelial cell growth factor A (VEGF-A) induces intracellular synthesis of the components of prothrombinase. All experiments were typically done three times but in some cases at least twice. A: bEnd. 3 cells were incubated for 1 hour at $37^{\circ} \mathrm{C}$ without or with VEGF-A ( $\left.30 \mathrm{ng} / \mathrm{mL}\right)$ and mRNA expression of prothrombinase components [coagulation factors II (FII), V (FV), X (FX), and VII (FVII)] assayed by real-time quantitative PCR (qPCR). mRNA was normalized to $\beta$-actin. B: bEnd. 3 cells were incubated for 72 hours at $37^{\circ} \mathrm{C}$ with media alone $(0.05 \%$ fetal bovine serum) or with VEGF-A $(30 \mathrm{ng} / \mathrm{mL})$, after which their culture supernatants were assayed for their abilities to accelerate the clotting times of human plasmas deficient in FII, FV, FVII, or FX (media control without cells was $<0.01 \mathrm{U} / \mathrm{mL}$ ). C: Human aortic endothelial cell (HAECs) were incubated for 72 hours at $37^{\circ} \mathrm{C}$ without or with VEGF-A $(30 \mathrm{ng} / \mathrm{mL}$ ), and coagulation assays were performed as in B (media control was $<0.01 \mathrm{U} / \mathrm{mL}$ ). D: RNA from thoroughly perfused aortae of wildtype (WT) mice was assayed for tissue factor, FII, FV, and FX mRNA levels by qPCR. E: Matrigel plugs were implanted into the flanks of WT mice for 10 days. Plugs were harvested, embedded in OCT compound, and sectioned. Sections were stained with anti-FII, anti-FV, anti-FVII, or anti-FX (each red) and counterstained with anti-CD31 (green). Nuclei were visualized with DAPI (blue). Background signaling was minimal and suppressed. The data are representative of six separate images. ${ }^{*} P<0.05$.

WA), SigmaPlot (Systat Software, Chicago, IL), or GraphPad Prism 6, with a significance threshold value of $P<0.05$. Except where indicated, all experiments were repeated at least two times in separate samples. Data are presented as mean values with SD.

\section{Results}

ECs Synthesize Coagulation Factors, and the Synthesis Is Up-Regulated by VEGF-A

To test whether ECs endogenously synthesize coagulation factors and, if so, whether VEGF-A stimulation affects their synthesis, a culture system with noncontact inhibited ECs was used to model EC growth as occurs in blood vessel reconstitution. Initial cell numbers were plated such that cells would remain $<70 \%$ confluent in the presence of VEGF-A at the longest incubation time. In initial studies, murine bEnd.3 ECs incubated for 1 hour were used in the absence or presence of added VEGF-A. Immediately after harvesting the ECs, the washed cells were assayed for coagulation factor mRNA transcripts. The cells incubated with VEGF-A showed $350 \%$ to $500 \%$ increased amounts of FV, FX, FVII, and FII (prothrombin) mRNAs adjusted to fold increases over media alone (Figure 1A). Whether the mRNA synthesis translates to protein synthesis by measuring coagulation factors in culture supernatants was assessed next. Supernatants of the cells incubated in media alone shortened the clotting times of plasma samples selectively deficient in FII, FV, FVII, and FX (Figure 1B), whereas those of VEGF-A-treated cells more profoundly shortened the clotting times of each (Figure 1B). Primary aortic endothelial cells (HAECs) were used to document that the findings apply to nontransformed primary cells and human ECs. Incubation of HAECs without or with human VEGF-A showed comparable coagulation factor mRNA production (Figure 1C). These data point to endogenous production of functional FV, FX, FVII, and FII by ECs tonically and augmented production of each in response to VEGF-A stimulation.

As a first test of whether the EC coagulation factor synthesis occurs in vivo, FV, FX, FVII, and FII production was examined 


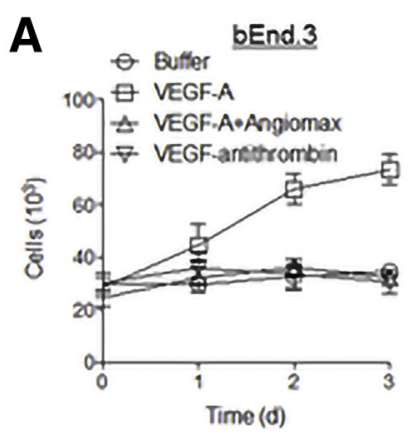

B bEnd.3

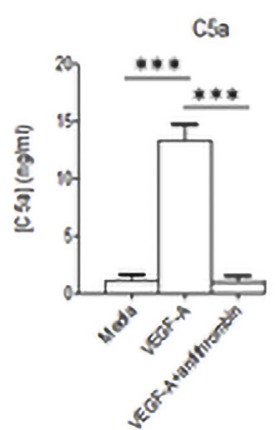

D

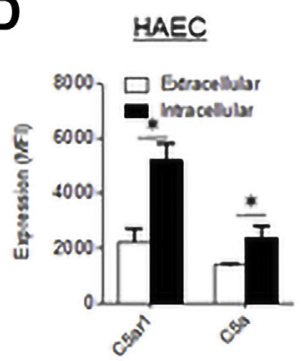

E

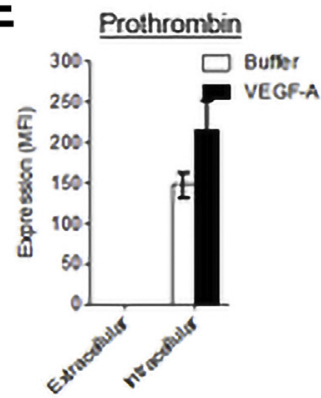

C bEnd.3
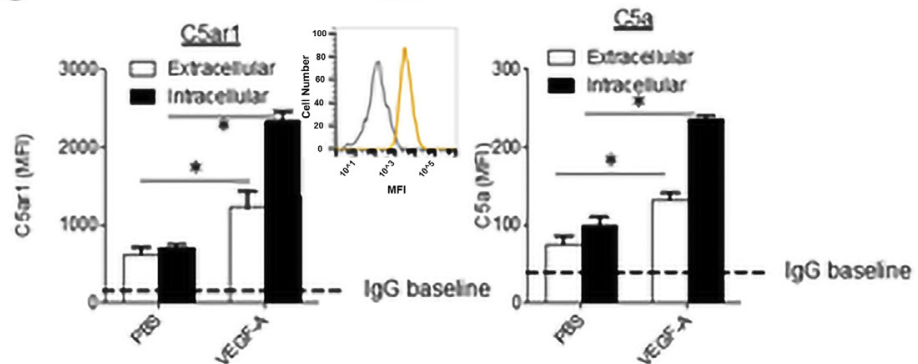

$\mathbf{F}$

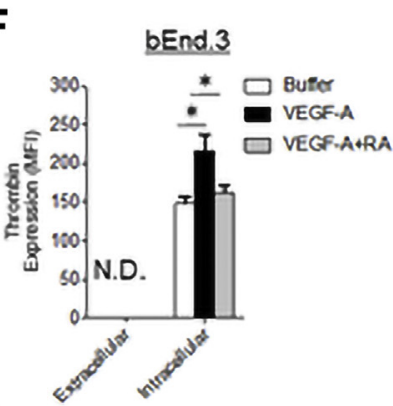

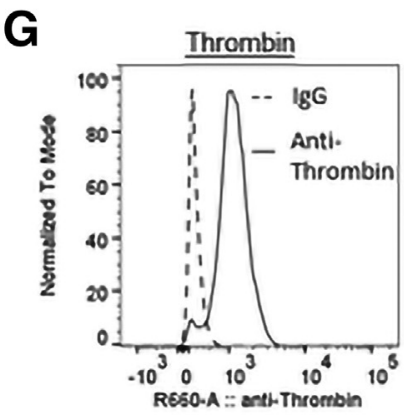

Figure 2 Vascular endothelial cell growth factor A (VEGF-A) induces intracellular generation of C5a, C5a receptor-1 (C5ar1), and thrombin. A: bEnd.3 cells were incubated for 72 hours at $37^{\circ} \mathrm{C}$ without or with VEGF-A $(30 \mathrm{ng} / \mathrm{mL})$ alone, VEGF-A $(30 \mathrm{ng} / \mathrm{mL})+$ bivalirudin (Angiomax; $\left.25 \mu \mathrm{g} / \mathrm{mL}\right)$, or VEGF$A+$ antithrombin $(1 \mu \mathrm{mol} / \mathrm{mL})$, and cell numbers were counted at 24,48 , and 72 hours. The $0.05 \%$ fetal bovine serum (FBS) was used to exclude effects of other growth factors or mediators in 10\% FBS. Antithrombin can inhibit VEGF-A binding to VEGF receptor 2 but only after its cleavage, resulting from its inactivation of thrombin. B: bEnd. 3 cells were incubated for 72 hours at $37^{\circ} \mathrm{C}$ without or with VEGF-A $(30 \mathrm{ng} / \mathrm{mL})$, or VEGF-A + antithrombin $(1 \mu \mathrm{mol} / \mathrm{mL})$, after which $\mathrm{C} 5 \mathrm{a}$ in culture supernatants was assayed by enzyme-linked immunosorbent assay. $\mathbf{C}$ and $\mathbf{D}$ : bEnd.3 cells (C) and human aortic endothelial cells (HAECs; D) were incubated with VEGF-A $(30 \mathrm{ng} / \mathrm{mL})$ for 24 hours, after which intracellular and extracellular C5a and C5ar1 were measured by flow cytometry. E: bEnd. 3 cells were incubated for 48 hours at $37^{\circ} \mathrm{C}$ with VEGF-A $(30 \mathrm{ng} / \mathrm{mL})$, after which cells were assayed for anti-total factor II (FII) reactivity extracellularly and intracellularly via flow cytometry. F: bEnd. 3 cells were incubated for 48 hours at $37^{\circ} \mathrm{C}$ with VEGF-A $(30 \mathrm{ng} / \mathrm{mL}) \pm \mathrm{C} 3 \mathrm{ar} 1-\mathrm{A} / \mathrm{C} 5 \mathrm{ar} 1-\mathrm{A}(10 \mathrm{ng} / \mathrm{mL}$ each) (RA = combined C3ar1 and C5ar1 antagonists), after which cells were assayed for anti-total FII reactivity extracellularly and intracellularly via flow cytometry. G: HAECs were pre-incubated for 2 days in serum-free media, after which the cells were assayed for specific anti-thrombin reactivity intracellularly via flow cytometry. ${ }^{*} P<0.05,{ }^{* *} P<0.001$. MFI, mean fluorescence intensity; N.D., not detectable.

in thoroughly perfused aortae from WT mice. Real-time quantitative PCR of dispase extracts were used to documente FII, FV, and FX as well as tissue factor mRNA expression (Figure 1D). Because aortae contain other cell types (eg, smooth muscle cells), and aortic ECs in situ do not proliferate (under homeostatic conditions), Matrigel plugs were implanted into the flanks of WT mice, plugs were removed 10 days later, and blood vessel growth was examined ${ }^{26}$ for intracellular coagulation factors. Confocal microscopy showed abundant FV, FX, FVII, and FII in EC cell bodies that colocalized with the EC marker CD31 (Figure 1E). These studies support the concept that the EC coagulation protein synthesis operates in vivo in proliferating ECs.

\section{Thrombin Generation of C5a in ECs Is Integral to VEGF-A Mitotic Function}

Whether EC coagulation factor production generates EC thrombin and, if so, whether the endogenously produced thrombin is mechanistically interconnected with VEGF-A mitotic function was tested next. Bivalirudin (Angiomax) or antithrombin (two different thrombin-specific inhibitors) was added to (nonconfluent) growing cultures of bEnd.3 cells in the absence or presence of added VEGF-A and EC proliferation was assessed over 72 hours. Consistent with the EC coagulation factor production being mechanistically tied to EC growth, both inhibitors completely abolished VEGF-A's induction of EC proliferation (Figure 2A). The thrombin active site inhibitors PPACK and FM19 had a similar abrogating effect (data not shown), supporting an essential role of EC coagulation factor synthesis in VEGF-A function. Taken together with the recent findings ${ }^{16}$ that ECproduced C5a plays a requisite role in EC growth, these data point to VEGF-A mitotic function, depending on activation of both EC-produced complement components and coagulation factors.

The earlier studies of the neo-intimal response to femoral artery wounding ${ }^{27}$ implicated C5ar1 signaling in the proliferation of ECs into wounds but presumed that the C5a activating ligand was derived from plasma $\mathrm{C} 5$. On the basis of these earlier findings, the above thrombin blockade data herein, and the earlier report that thrombin can cleave C5a from purified C5 in vitro, ${ }^{17}$ we hypothesized that $\mathrm{C} 5 \mathrm{a}$ in the setting of EC growth would derive from cleavage of EC 

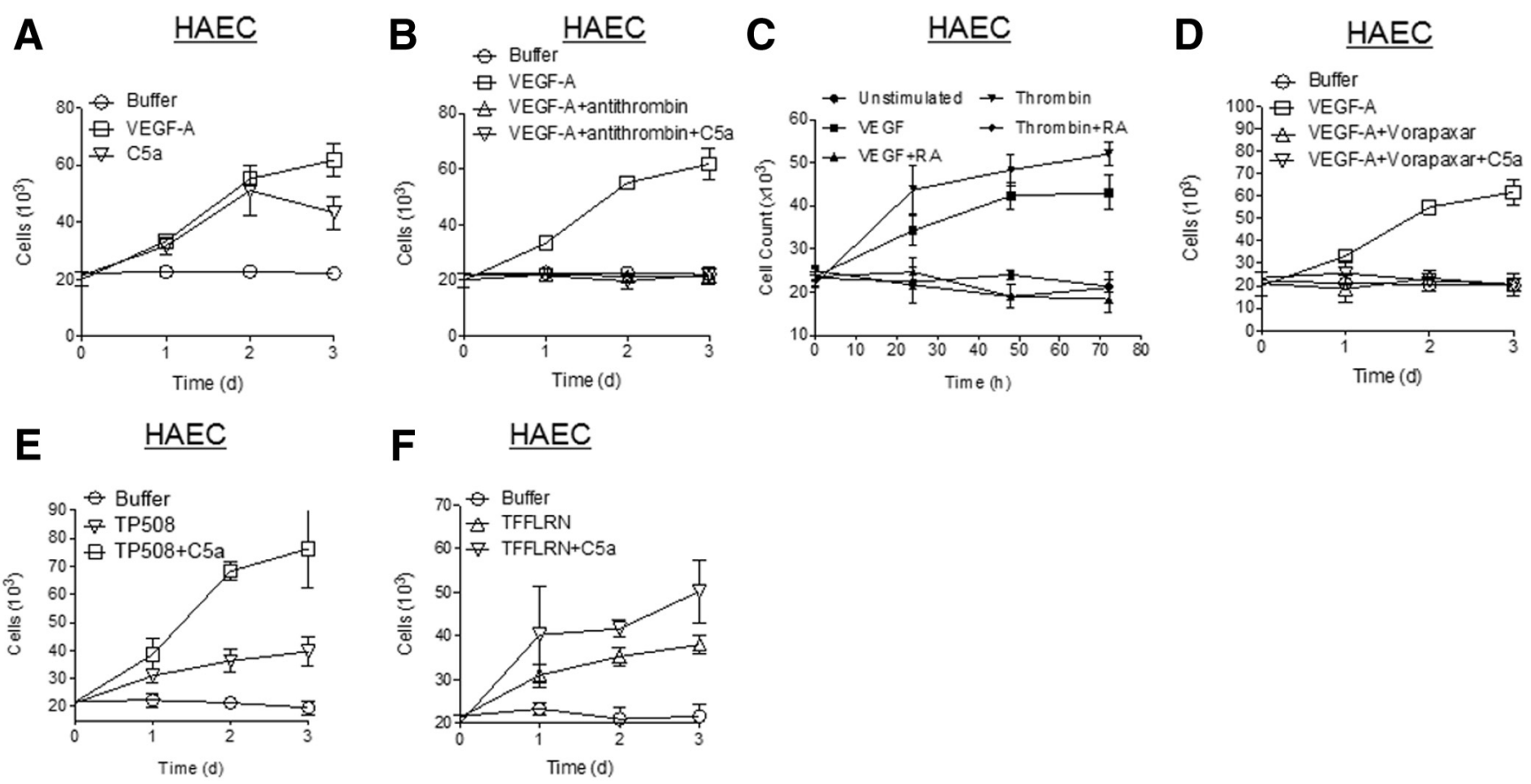

Figure 3 Combinatorial C5a receptor-1 (C5ar1) and protease-activated receptor signaling is required for endothelial cell (EC) growth. All experiments were performed two or more times. A: Human aortic ECs (HAECS) were incubated for 72 hours at $37^{\circ} \mathrm{C}$ without or with vascular endothelial cell growth factor A (VEGF-A; $30 \mathrm{ng} / \mathrm{mL})$ or $\mathrm{C} 5 \mathrm{a}(30 \mathrm{ng} / \mathrm{mL})$, and cell numbers were counted at $0,24,48$, and 72 hours. B: HAECs were incubated for 72 hours at $37^{\circ} \mathrm{C}$ without or with VEGF-A $(30 \mathrm{ng} / \mathrm{mL})$ alone, VEGF-A + antithrombin $(1 \mu \mathrm{mol} / \mathrm{mL})$, or VEGF-A + antithrombin $+\mathrm{C5a}(10 \mathrm{ng} / \mathrm{mL})$, and cell numbers were counted at $0,24,48$, and 72 hours. C: HAECs were incubated at $37^{\circ} \mathrm{C}$ without or with VEGF-A (30 ng/mL) alone, VEGF-A + C3ar1-A/C5ar1-A (10 ng/mL each), thrombin $(1 \mathrm{nmol} / \mathrm{mL})$, or thrombin + C3ar1-A/C5ar1-A, and cell numbers were counted over 3 days. D: HAECs were incubated at $37^{\circ} \mathrm{C}$ with VEGF-A (30 ng/mL), VEGF-A $(30 \mathrm{ng} / \mathrm{mL})+\operatorname{vorapaxar}(10 \mathrm{ng} / \mathrm{mL})$, or VEGF-A $(30 \mathrm{ng} / \mathrm{mL})+\operatorname{vorapaxar}(10 \mathrm{ng} / \mathrm{mL})+$ C5a $(10 \mathrm{ng} / \mathrm{mL})$, and cell numbers were counted as in D. E: HAECs were incubated for 72 hours at $37^{\circ} \mathrm{C}$ without or with TP508 $(10 \mu \mathrm{g} / \mathrm{mL})$ or TP508 $(10 \mu \mathrm{g} / \mathrm{mL})$ plus C5a $(10 \mathrm{ng} / \mathrm{mL})$, and cell numbers were counted at $0,24,48$, and 72 hours. F: The experiment in $\mathbf{E}$ was repeated, substituting TFLLRN $(5 \mu \mathrm{g} / \mathrm{mL})$ for TP508.

produced C5 by EC produced thrombin. To test this idea, proliferating (nonconfluent) bEnd. 3 cells were cultured with VEGF-A with or without antithrombin and the cells and their culture supernatants were assayed for C5a. Abundant C5a was generated in cultures with VEGF-A alone, whereas little, if any, was generated in the presence of thrombin blockade by antithrombin (Figure 2B). To directly determine whether VEGF-A augments thrombin-induced C5a production and determine whether the process is localized within ECs, unstimulated and VEGF-A-stimulated bEnd.3 cells were assayed for $\mathrm{C} 5 \mathrm{a}$ without or with permeabilization of the cells. VEGF-A stimulation augmented the production of C5a as well as its C5ar1 receptor; and EC permeabilization showed that both augmentations occurred predominantly intracellularly within the ECs (Figure 2C). To verify that the findings apply to primary cells and human ECs, studies were repeated with HAECs. Comparable results were obtained (Figure 2D). Similar to that in the EC-produced C5a deriving from thrombin cleavage of EC-produced C5, added VEGF-A concomitantly augmented a prothrombin/thrombin signal intracellularly in the ECs (Figure 2E). The elicited prothrombin/thrombin signal was blunted by pharmaceutical blockade of C5ar1 (Figure 2F) interconnecting EC thrombin generation and EC C5a production. These results are consistent with the previous studies connecting VEGF-A induction of EC growth with up-regulation of autocrine C5ar1 signaling occurring intracellularly in endosomes. ${ }^{16}$

To exclude the possibility that the thrombin-induced cleavage of C5a in ECs resulted from prothrombin contained in the bovine serum-supplemented medium and document that the intracellular prothrombin/thrombin signal induced by VEGF-A contained thrombin, the primary HAECs were cultured in serum-free medium for 2 days. Intracellular fluorescence-activated cell sorting of the serum-free cells with a thrombin-specific monoclonal $\mathrm{Ab}$ $(\mathrm{mAb}$; that does recognize prothrombin) showed a homogeneously positive anti-thrombin signal (Figure 2G). These data linking VEGF-A with intracellular generation of both thrombin and C5a taken together with the finding that antithrombin blocked the EC C5a production (Figure 1G) pointed to $\mathrm{C} 5 \mathrm{a}$ being generated by EC produced thrombin, an issue that will be further examined below.

\section{Locally Produced Thrombin Induces Cooperative C5ar1 and PAR Signaling That Promotes EC Proliferation}

The generation of both thrombin and C5a intracellularly in proliferating ECs raised the question of whether VEGF-A induction of EC growth is dependent on the heightened generation of both. Adding C5a to primary cultures of 

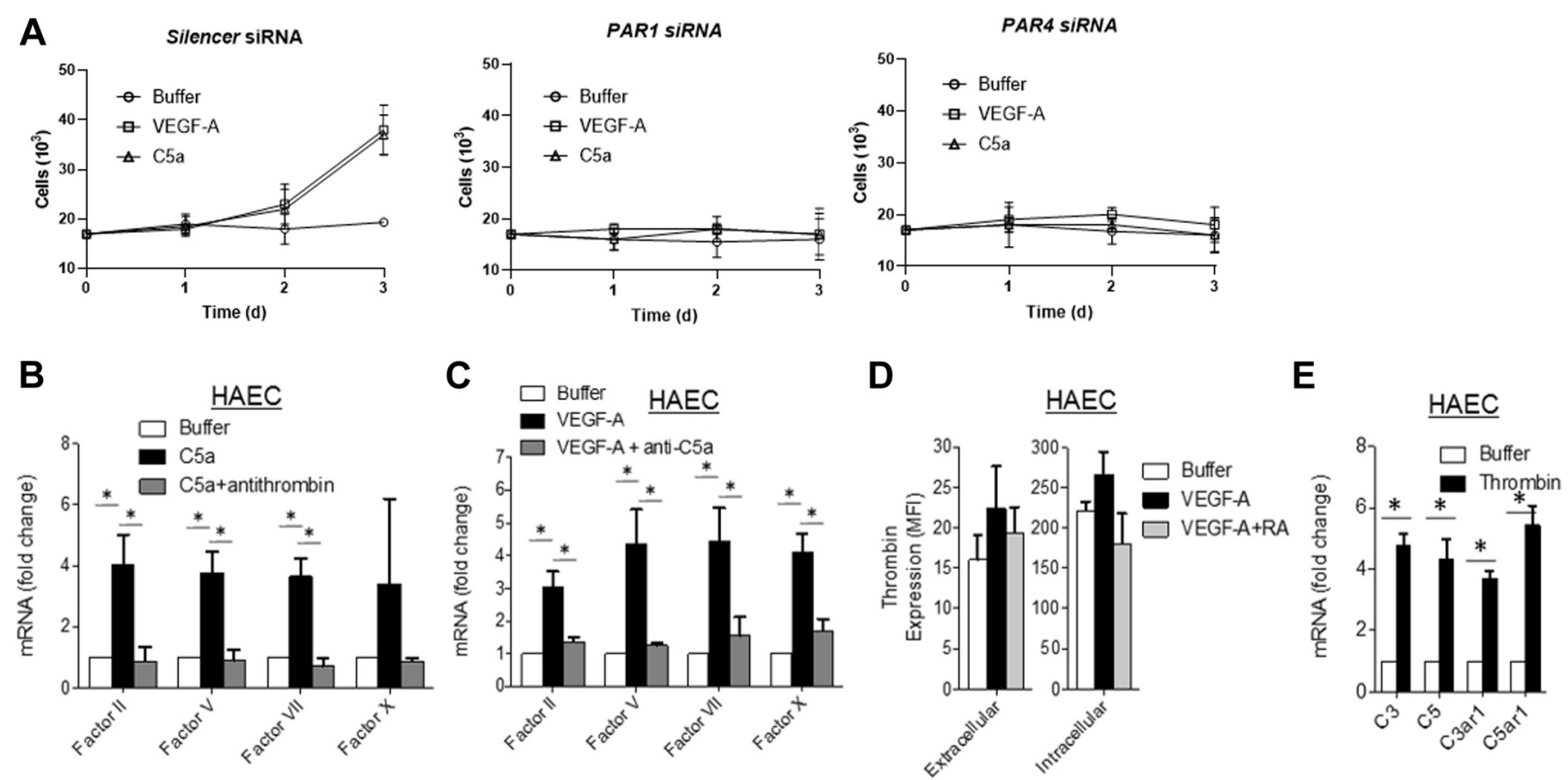

Figure 4 Autocrine protease-activated receptor (PAR) 1/4 signaling is required for vascular endothelial cell growth factor A (VEGF-A) mitotic function, and endothelial cell (EC) prothrombinase and complement production depend on each other. A: Human aortic ECs (HAECs) were treated with siRNA targeting either PAR1 or PAR4 (or nonspecific control, Silencer) for 7 days. Following confirmation of knockdown, cells were pre-incubated for 16 hours in serum-free medium and then treated with VEGF-A $(30 \mathrm{ng} / \mathrm{mL})$ or $\mathrm{C} 5 \mathrm{a}(30 \mathrm{ng} / \mathrm{mL})$ for 3 days (in serum-free media), and growth was measured. As our studies ${ }^{16,33}$ have shown that VEGF receptor 2 (VEGFR2) signaling depends on PAR1 and PAR4 signaling (Figure 3), the loss of the VEGF-A response likely involved reduced VEGFR2 expression. B: HAECs were incubated for 1 hour at $37^{\circ} \mathrm{C}$ without or with $\mathrm{C} 5 \mathrm{a}(10 \mathrm{ng} / \mathrm{mL})$ or $\mathrm{C} 5 \mathrm{a}+$ plus antithrombin $(1 \mu \mathrm{mol} / \mathrm{mL})$, and cells were assayed for factor II (FII), factor V (FV), factor VII (FVII), or factor X (FX) mRNAs by real-time quantitative PCR (qPCR). mRNA was normalized to glyceraldehyde-3phosphate dehydrogenase (GAPDH). The anti-C5a monoclonal antibody (mAb) recognizes a neoepitope not present in the parental C5 protein. C: HAECS were incubated for 1 hour at $37^{\circ} \mathrm{C}$ without and with VEGF-A (30 ng/mL), or VEGF-A + anti-C5a mAb $(1 \mu \mathrm{g} / \mathrm{mL})$, and cells were assayed for FII, FV, FVII, and FX mRNAs by qPCR. mRNA was normalized to GAPDH. D: HAECs were incubated for 48 hours with VEGF-A ( $30 \mathrm{ng} / \mathrm{mL}) \pm$ C3ar1-A/C5ar1-A (10 ng/mL each), after which cells were assayed for anti-total FII reactivity extracellularly and intracellularly by flow cytometry. E: HAECs were incubated for 1 hour at $37^{\circ} \mathrm{C}$ without or with thrombin $(1 \mathrm{nmol} / \mathrm{mL})$, and cells were assayed for C3, C5, C3ar1, and C5ar1 mRNAs by qPCR. mRNA was normalized to GAPDH. ${ }^{\star} P<0.05$.

HAEC (or to murine bEnd.3 cells) induced cell growth similar to adding VEGF-A (Figure 3A and Supplemental Figure S1A, E, and F). On the other hand, VEGF-A failed to induce growth when thrombin generation was blocked with antithrombin, even if C5a was included in the cultures (Figure 3B and Supplemental Figure S1B). Adding thrombin, like adding C5a, similarly induced the growth of both primary HAEC and bEnd.3 cells with efficiency comparable to adding VEGF-A (Figure 2C), whereas thrombin failed to do so if C5ar1 signaling was blocked by C5ar1 pharmaceutical antagonism (RA:C3ar1/C5ar1 antagonists) (Figure 3C and Supplemental Figure S1C). The findings that $\mathrm{C} 5 \mathrm{a}$ and thrombin induced $\mathrm{EC}$ proliferation only in the presence of each other pointed to a mechanism in which both are jointly involved in EC growth. Neither by itself was sufficient for optimal VEGF-A induction of EC growth.

The failure of VEGF-A to induce EC growth in the presence of thrombin blockade, despite supplying its C5a product, raised the question of whether thrombin additionally provides for VEGF-A mitotic signaling via signaling through EC expressed PAR(s). ${ }^{28}$ As a first test of this idea, bEnd.3 cells (which express PAR1 and PAR4) were incubated with VEGF-A with or without vorapaxar, a drug known to inhibit human PAR1 signaling. ${ }^{29,30}$ The added vorapaxar abolished VEGF-A induction of (murine) bEnd.3 cell growth (Supplemental Figure S1D), as well as primary (human) HAEC growth (Figure 3D), irrespective of supplementing the cultures with excess C5a.

Seemingly inconsistent with the above findings, a prior study ${ }^{31}$ using confluent HUVECs found that thrombin induction of PAR1 signaling suppresses rather than promotes EC proliferation in response to epidermal growth factor and does so by disabling AKT phosphorylation. On the basis of the current data, we hypothesized that in proliferating ECs, in contrast to confluent HUVECs, which are contact inhibited, PAR signaling confers different signals. To test this concept, bEnd.3 cells and primary HAECs were cultured with TP508 (a 23-amino acid peptide from thrombin; ie, a portion of the PAR1 receptor-binding domain of thrombin) or with TFLLRN (an agonist peptide corresponding to the peptide sequence of the tethered PAR1 ligand). Each agonist was added individually, or in combination with C5a, to primary HAEC or bEnd.3 cells and EC proliferation was assessed. Although each PAR1 agonist alone induced primary HAEC (Figure 3, E and F) and 

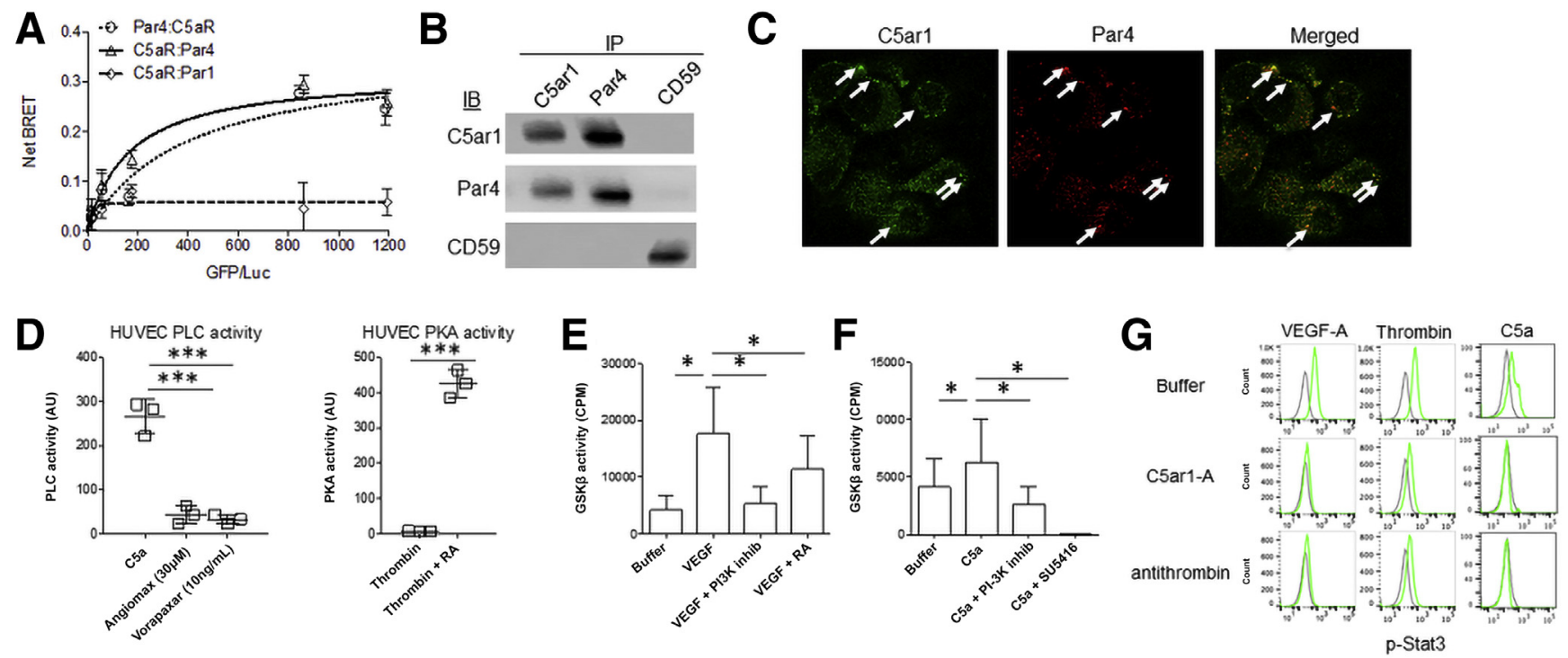

Figure 5 C5a receptor-1 C5ar1) and protease-activated receptors (PARs) closely interact, and phospholipase C (PLC), AKT-glycogen synthase kinase (GSK)$3 \beta$, and STAT3 activation depends on their joint signaling. All experiments were performed two or more times. A: Human 293 cells cotransfected with C5ar1-green fluorescent protein (GFP) + PAR4-luciferase (Luc), PAR4-GFP + C5ar1-Luc, or alternatively with C5ar1-GFP + PAR1-Luc, or PAR1-GFP + C5ar1Luc. Cells also were transfected with PAR4-GFP + PAR4-Luc as a positive control. Bioluminescence resonance energy transfer (BRET) in each combination was measured after addition of Luc substrate. B: Anti-PAR4 immunoprecipitations (IPs), anti-C5ar1 IPs, and anti-CD59 IPs were prepared from bEnd.3 cell extracts, and immunoblots of the immunoprecipitated proteins were probed for associated C5ar1, PAR4, or CD59. C: bEnd.3 cells in complete media were incubated with vascular endothelial cell growth factor A (VEGF-A; $30 \mathrm{ng} / \mathrm{mL}$ ) for 1 hour, after which the fixed and permeabilized cells were stained with anti-C5ar1-GFP and anti-PAR4-RFP and examined by confocal microscopy. Background signaling was minimal and suppressed. The data are representative of six separate images. Arrows represent sites of colocalization. D: Left panel: Human umbilical vein endothelial cells (HUVECs) were stimulated with C5a or C5a plus bivalirudin (Angiomax) or vorapaxar for 5 minutes, after which cells were lysed and assayed for PLC activity. Right panel: HUVECs were stimulated with thrombin or thrombin plus C3ar1-A/C5ar1-A (RA) for 5 minutes, after which cells were lysed and assayed for protein kinase A (PKA) activity. E: Serum-starved bEnd.3 cells were incubated for 72 hours at $37^{\circ} \mathrm{C}$ without or with VEGF-A $(30 \mathrm{ng} / \mathrm{mL})$, VEGF-A + the PI-3K $\gamma$ inhibitor AS252424 $(10 \mu \mathrm{mol} / \mathrm{mL})$, or VEGF-A + C3ar1-A/C5ar1-

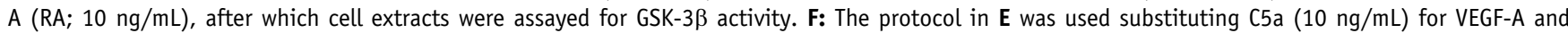
including C5a + the PI-3K $\gamma$ inhibitor AS252424 $(10 \mu \mathrm{g} / \mathrm{mL})$ and C5a + the VEGFR2 inhibitor SU5416 $(10 \mu \mathrm{mol} / \mathrm{mL})$. G: bEnd.3 cells were incubated with VEGFA $(30 \mathrm{ng} / \mathrm{mL})$, thrombin $(1 \mu \mathrm{mol} / \mathrm{mL})$, or $C 5 \mathrm{a}(10 \mathrm{ng} / \mathrm{mL})$ in the absence or presence of C5ar1-A $(\mathrm{RA} ; 10 \mathrm{ng} / \mathrm{mL})$ or antithrombin $(1 \mu \mathrm{mol} / \mathrm{mL})$, after which the cells were assayed for phosphorylated STAT3 (p-STAT3) by intracellular flow cytometry. ${ }^{*} P<0.05,{ }^{* *} P<0.001$. AU, arbitrary unit; CPM, counts per minute; IB, immunoblot.

bEnd. 3 cell growth (Supplemental Figure S1, G and H), the inclusion of C5a had an additive effect. These findings argue that in growing ECs, PAR1 signaling augments rather than suppresses growth and that it coordinates with C5ar1 signaling in promoting EC growth. Additional studies comparing growing and confluent HAECs are discussed below.

Vorapaxar not only inhibits PAR1 signaling but also can impact PAR4 signaling as it makes heterodimers with PAR4 that coordinate in platelet activation ${ }^{32}$ in a time-dependent manner. ${ }^{6}$ siRNA studies were performed to determine whether thrombin's induction of EC growth involves PAR4 as well as PAR1 signaling and establish whether the activation of both is required for VEGF-A mitotic function. To exclude thrombin in serum, serum-free conditions were used. HAECs were treated with siRNAs targeting PARl or PAR4, or with Silencer (non-specific) siRNA control. Flow cytometry verified that the specific siRNAs fully abolished PAR1 and PAR4 cell surface expression (Supplemental Figure S2). The alternatively treated HAECs were first pre-incubated in serum-free medium for 16 hours, and then VEGF-A induced growth was examined over an additional
72 hours, maintaining the HAECs in serum-free medium. In contrast to the Silencer siRNA treated HAECs, which robustly grew in response to either VEGF-A or C5a (Figure 4A), the HAECs silenced in either PARI or PAR4 showed no growth when incubated with either agonist (Figure 4A). ${ }^{33}$

\section{EC-Produced Thrombin Modulates EC C5a Production and Vice Versa}

The codependence of VEGF-A mitotic function on both endogenous thrombin and C5a prompted studies of whether augmented complement component and coagulation factor production induced by VEGF-A regulate each other. Adding C5a to cultures of HAEC or of bEnd.3 cells up-regulated mRNA expression of all of the EC produced coagulation proteins (Figure 4B and Supplemental Figure S1I), and antithrombin inhibited all of the up-regulations (Figure 4B and Supplemental Figure S1I). Conversely, disrupting C5ar1 signaling with a (blocking) anti-C5a mAb prevented VEGFA's up-regulation of coagulation factor mRNAs (Figure 4C and Supplemental Figure S1J). Consistent with this, the C5ar1 
blockade repressed VEGF-A's induction of intracellular prothrombin/thrombin generation (Figure 4D and Supplemental Figure $\mathrm{S} 1 \mathrm{~K}$ ) (the intracellular ordinate axis is 10 -fold higher than that of the extracellular ordinate axis). These data indicate that coagulation factor synthesis depends on EC C5ar1 signaling. In accordance with the mRNA expression interdependence occurring reciprocally, added thrombin up-regulated EC complement component mRNA expression (Figure 4E and Supplemental Figure S1K).

These findings point to VEGF-A's induction of autocrine PAR signaling and autocrine C5ar1 signaling occurring coordinately in ECs. The findings also point to the two systems regulating each other by virtue of thrombin being needed for generation of $\mathrm{C} 5 \mathrm{a}$, and C5ar1 signaling being needed for coagulation protein synthesis (Figure 4, C and D). Taken together, these data indicate that endogenous complement production in ECs up-regulates endogenous prothrombinase production and vice versa and that both up-regulations play requisite roles in VEGF-A mitotic signaling.

C5ar1 and PAR4 Are Associated, and Their Joint Signaling Is Interconnected in ECs

Because locally produced thrombin in ECs elicited joint C5ar1 and PAR signaling, we hypothesized that PAR1, PAR4, or both ${ }^{3}$ and C5ar1 might be in proximate contact. To test this idea, BRET analyses were done first. HEK293 (human kidney epithelial cells) cells were cotransfected with C5ar1-GFP together with PAR1-luciferase or with PAR4-luciferase. There was a dose-dependent energy transfer in the cells containing C5ar1 plus PAR4-luciferase (Figure 5A), but not PAR1-luciferase (Figure 5A). A reverse analysis with C5ar1-luciferase and PAR4-GFP yielded the same positive result (Figure 5A). These data indicate that C5ar1 and PAR4 are within $10 \mathrm{~nm}$ of each other in membranes. Co-immunoprecipitation assays were performed next. In support of the BRET data, anti-C5ar1 coimmunoprecipitated PAR4 and vice versa (Figure 5B), but PAR1 was not brought down in either immunoprecipitation (Figure 5B). Finally, confocal imaging with GFP-labeled anti-C5ar1 mAb and Red Fluorescent Protein (RFP)labeled anti-PAR4 $\mathrm{mAb}$ showed colocalization of the two receptors (Figure 5C). These results pointed to a functionally interactive complex between PAR4 and C5ar1, an arrangement that could facilitate thrombin's ability to concurrently produce the C5ar1 and PAR4 ligands and coordinately elicit signaling ${ }^{34}$ by the two receptors.

Because C5ar1 and PAR4 are both GPCRs, their association raised the possibility of the existence of additional signaling interconnections. C5ar1 [as indicated (Introduction)], is a Gi coupled GPCR such that the $\alpha$ subunit of its G protein represses activation of adenylyl cyclase. PAR4 is (predominantly) a Gq coupled GPCR such that its G protein $\alpha$ subunit activates phospholipase C (PLC). Some past studies have reported that C5ar1 can couple to $\mathrm{G} \alpha \mathrm{q}$ as well as Gai. ${ }^{35-38}$ Others have reported that PAR4 can couple to $\mathrm{G} \alpha \mathrm{i}$ as well as $\mathrm{G} \alpha \mathrm{q}{ }^{3,5,7}$ To determine whether combinatorial C5ar1-PAR signaling might reconcile these observations, HUVECs were incubated with C5a alone, together with Angiomax (which blocks thrombin), or together with vorapaxar (which blocks PAR1/PAR4 signaling) (Figure 3D) and PLC activation was assayed. C5a activation of the G $\alpha$ q target PLC occurred when C5a was added alone (Figure 5D), but the activation was reversed by Angiomax that blocks thrombin needed for PAR as well as C5ar1 signaling. Notably, vorapaxar (which blocks PAR1-dependent PAR4 signaling) (Figure 3D) had the same effect (Figure 5D). In the case of the Gai signaling of PAR4, there have been reports that in platelets PAR4 can couple to the purinergic Gai GPCR P2Y12. ${ }^{34}$ Nevertheless, although thrombin suppressed protein kinase A activation (a result of suppressed generation of the Gai target adenylyl cyclase) in primary HAECs, it did not do so in the presence of C3ar1/C5ar1 pharmaceutical antagonists (RA) implicating C5ar1 signaling (Figure 5D). These data provide evidence that PLC can be activated by C5ar1 signaling and adenylyl cyclase can be repressed by PAR4 signaling. They argue that the cross-activation can occur by virtue of C5ar1 and PAR4 being functionally associated with each other in primary HAECs and the agonist of either GPCR being able to activate the other GPCR.

\section{Disruption of C5ar1 or PAR Transduction Blocks AKT-GSK- $\beta$-STAT3 and AKT-mammalian target of rapamycin 2 (mTOR) Signaling}

VEGF-A induction of EC proliferation is dependent on activated STAT3 $3{ }^{39}$ Previous studies in immune cells ${ }^{14}$ and recent studies in $\mathrm{ECs}^{16}$ showed that C5ar1 signaling promotes STAT3 activation. To determine whether, and how, combinatorial EC C5ar1 and PAR1/4 signaling participates in STAT3 activation, VEGF-A induction of AKT-GSK$\beta$-STAT3 signaling in ECs was examined. Addition of C5a, like that of VEGF-A (Figure 3A), to cultures of bEnd.3 cells evoked $S^{473}$ phosphorylation of AKT 14, activation of GSK- $\beta$ (Figure 5, E and F), and Y705 phosphorylation of STAT3 (Figure 5G). The activation of GSK- $\beta$ by VEGF-A was suppressed by C5ar1 blockade (Figure 5E) and that by C5a was reversed by VEGFR2 blockade (Figure 5F). STAT3 activation by VEGF-A was suppressed by either C5ar1 or thrombin blockade, and that by thrombin was suppressed by C5ar1 blockade (Figure 5G), consistent with both PAR4 and C5ar1 signaling being essential. GSK- $\beta$ activation by $\mathrm{C} 5$ a was abolished by the VEGFR2 inhibitor SU5416 (Figure 5F). GSK- $\beta$ activation by VEGF-A was abolished by the AS252424 inhibitor of phosphatidylinositol 3-kinase gamma (PI-3K $\gamma$ ) (Figure 5, E and F) (ie, downstream of both C5ar1 ${ }^{14}$ and PAR4 transduction ${ }^{40,41}$ and possibly related to either thrombin or C5a being able to activate both C5ar1 and PAR4). Collectively, these data argue that thrombin as well as C5ar1 signaling are needed 
A

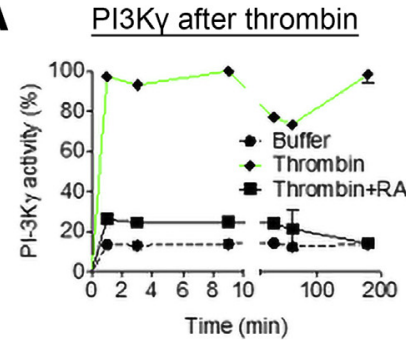

B Pl13Ka after thrombin

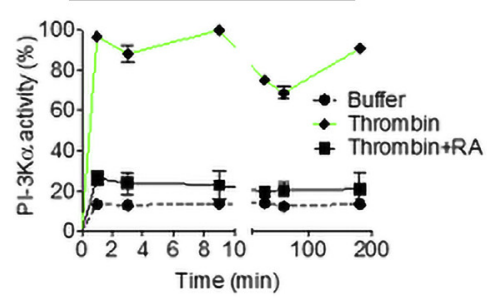

C

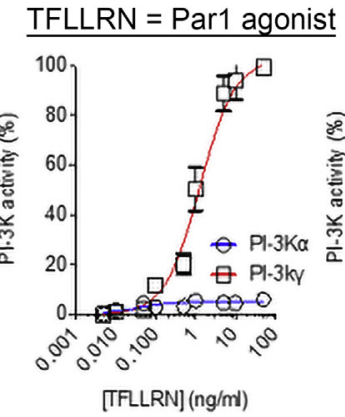

ay- $\mathrm{NH}_{2}=$ Par4 agonist

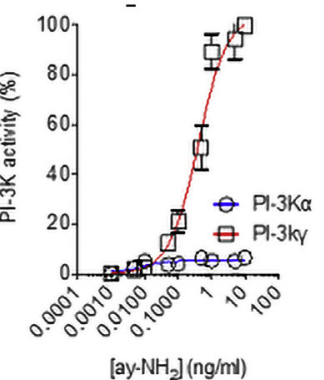

D

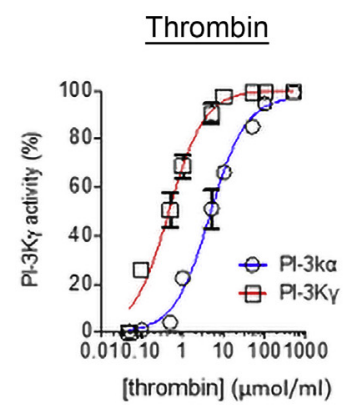

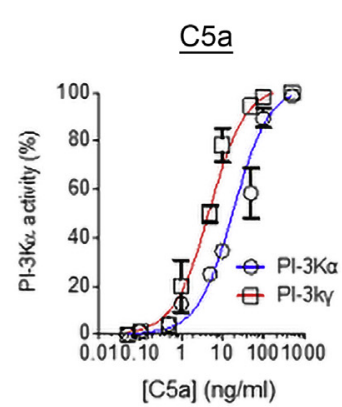

E

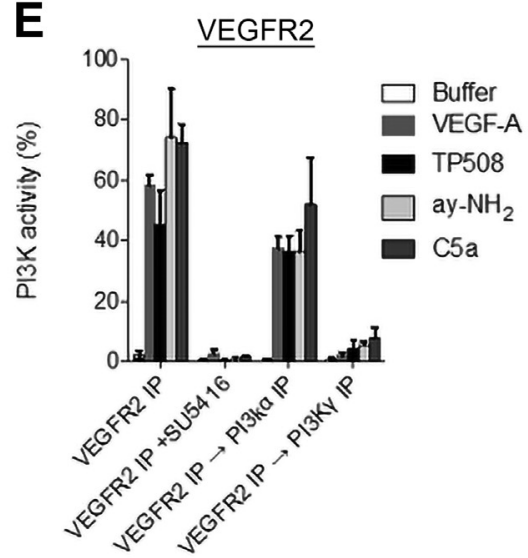

Figure 6 Role of C3ar1, protease-activated receptors (PAR) 1/PAR4, and vascular endothelial cell growth factor receptor 2 (VEGFR2) signaling in activation

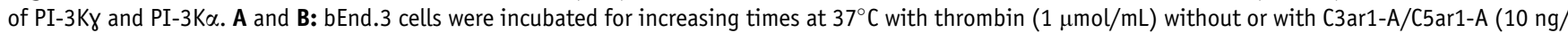
$\mathrm{mL}$ each), after which anti-PI-3K $\gamma(\mathbf{A})$ and anti-PI-3K $\alpha$ (B) immunoprecipitations (IPs) of the cell extracts were assayed for PI-3K enzymatic activity. C: TFLLRN (PAR1 agonist) or ay-NH2 (PAR4 agonist) was titrated into bEnd. 3 cells for 9 minutes at $37^{\circ} \mathrm{C}$, after which PI-3K isoform activity was assayed, as in $\mathbf{A}$ and B above. D: Thrombin $(1 \mu \mathrm{mol} / \mathrm{mL}$; left panel) or C5a $(10 \mathrm{ng} / \mathrm{mL}$; right panel) was titrated into serum-starved bEnd. 3 cells for 9 minutes, after which PI$3 \mathrm{~K}$ isoform activity was assayed as above. E: Vascular endothelial cell growth factor A (VEGF-A), TP508, ay-NH2, and C5a were incubated with bEnd.3 cells for 9 minutes, cells were lysed, and anti-VEGFR2 IPs were prepared. The VEGFR2 IPs were eluted using alkaline solution, and the eluents were immunoprecipitated with PI-3K $\alpha$ or PI-3K $\gamma$ Abs, after which PI-3K activity in the IPs was assayed as above.

for VEGFR2-associated induction of GSK- $\beta$ and STAT3 activation. The data further argue that AKT-GSK$\beta-$ STAT3 signaling is dependent on PI-3Kr activation.

\section{Both C5ar1 and PAR4 Signaling Promote VEGFR2 Signaling in ECs}

How joint C5ar1 and PAR1/4 signaling in ECs affects VEGF-A induction of the PI-3K-AKT-mTOR cascade was investigated next. Prior studies in $\mathrm{CD}^{+} \mathrm{T}$ cells ${ }^{12,14}$ showed that C5ar1 activation of $\mathrm{PI}-3 \mathrm{Kr}$ is essential for augmented PI-3K-AKT - mTOR signaling. In distinction to this linkage, early studies of $\mathrm{CD} 4^{+}$cell activation ${ }^{42}$ had linked costimulatory CD28-dependent activation of PI-3Ka with AKT-mTOR signaling. Taken together, the two results suggest that both activated PI-3K isoforms [that jointly promote phosphatidylinositol 3,4,5 trisphosphate (PIP3) assembly] may be needed for AKT-mTOR signaling in ECs as in $\mathrm{T}$ cells.

To characterize the respective roles of C5ar1 and of PAR4 signaling in PI-3Kr and of PI-3K $\alpha$ activation in the context of EC proliferation, bEnd.3 ECs were first incubated with thrombin and the activation of each PI-3K isoform was assayed. The added thrombin (which jointly induces both PAR4 and C5ar1 signaling) activated both PI-3K isoforms with high efficiency (Figure 6, A and B). The activation of both isoforms occurred in $<1$ minute and was sustained for $>180$ minutes (Figure 6, A and B). The activation of both isoforms was abolished by C5ar1 antagonism, highlighting C5ar1 signaling as an obligate process in thrombin-induced activation of the two PI-3K isoforms (Figure 6, A and B). To distinguish the roles of PAR1 and PAR4 in activating each PI-3K isoform, PAR agonists and antagonists were used. Titrations of agonists specific for PAR1 and PAR4 into cultures of (nonactivated) bEnd.3 cells showed that signaling by either PAR activated PI-3Kr but did not activate $\mathrm{PI}-3 \mathrm{~K} \alpha$ (Figure $6 \mathrm{C}$ ). This contrasted with titrations of $\mathrm{C} 5 \mathrm{a}$ into the culture, which activated both PI-3Kr and PI$3 \mathrm{~K} \alpha$, localizing the PI-3K $\alpha$ activating effect of thrombin (which jointly induces PAR and C5ar1 signaling) to C5ar1 signaling (Figure 6D). Dose-response curves of either thrombin or C5a addition to bEnd.3 cells indicated that activation of $\mathrm{PI}-3 \mathrm{~K} \gamma$ preceded that of PI-3K $\alpha$. This timing would be consistent with PI-3Kr functioning upstream to 

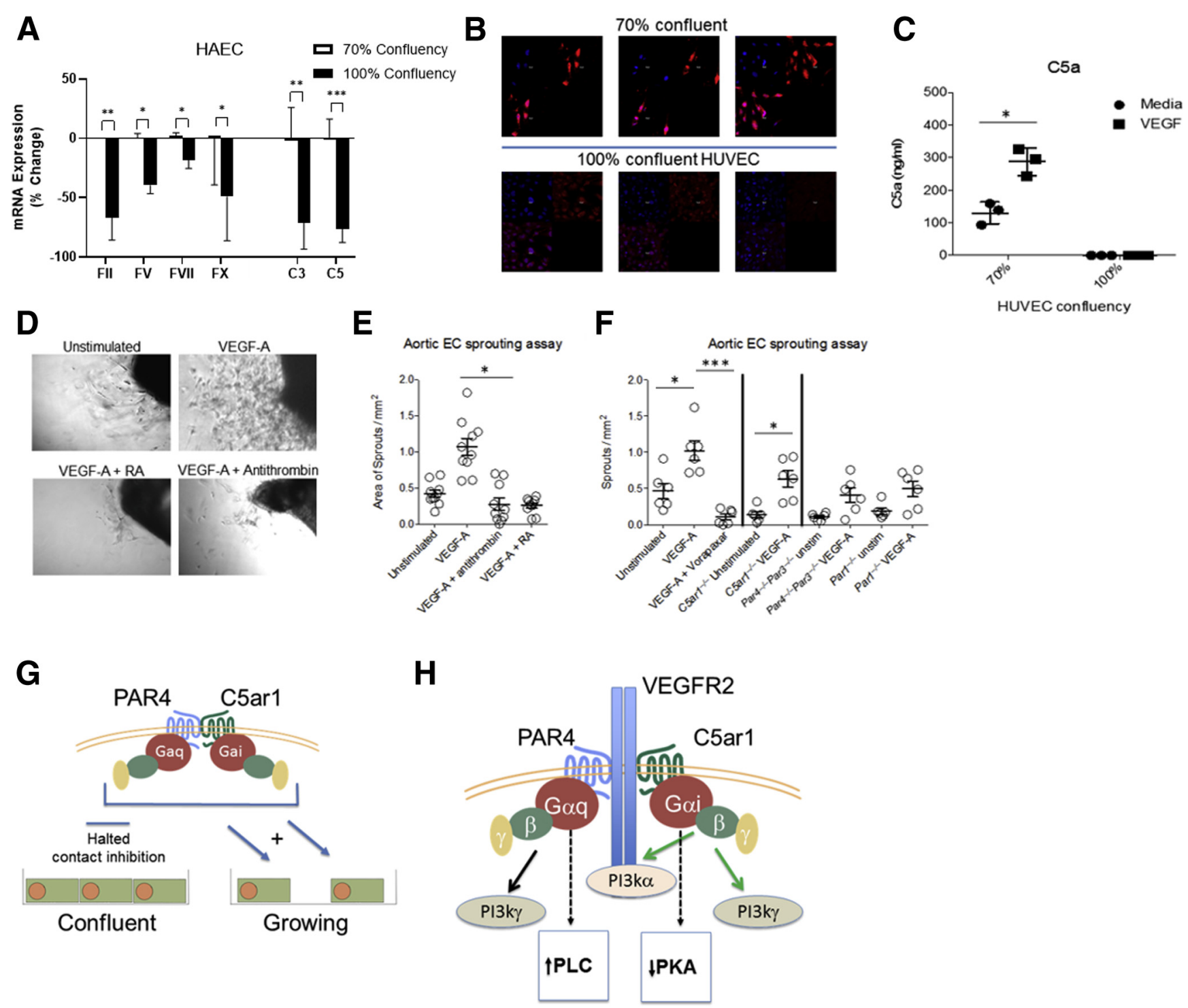

Figure 7 Combinatorial C5a receptor-1 (C5ar1) and thrombin agonism drives angiogenesis. The experiments were performed two or more times. A: Human aortic endothelial cell (HAECS) grown at $70 \%$ and $100 \%$ confluence were assayed for factor II (FII), factor V (FV), factor VII (FVII), factor X (FX), C3, and C5 mRNAs by real-time quantitative PCR. mRNA was normalized to glyceraldehyde-3-phosphate dehydrogenase. B: Human umbilical vein endothelial cells (HUVECs) grown at $70 \%$ or $100 \%$ confluence were stained with antibodies against FII (red), counterstained with DAPI (blue) and CD31 (data not shown), and imaged by confocal microscopy. Three randomly selected fields of view under each condition are presented. C: HUVECs grown at $70 \%$ or $100 \%$ confluence were stimulated with vascular endothelial cell growth factor A (VEGF-A; $30 \mathrm{ng} / \mathrm{mL}$ ) or media control for 24 hours, after which C5a in the culture supernatant was assayed by enzyme-linked immunosorbent assay. D: Representative sections of aortic segments from wild-type (WT) mice were incubated for 7 days in Matrigel with VEGF-A $(30 \mathrm{ng} / \mathrm{mL})$, VEGF-A + C3ar1-A/C5ar1-A (RA; $10 \mathrm{ng} / \mathrm{mL}$ each), or VEGF-A + antithrombin $(1 \mu \mathrm{mol} / \mathrm{mL})$. E: Quantitation of sprout areas from WT aortic segments grown without or with VEGF-A, VEGF-A + C3ar1-A/C5ar1-A, or VEGF-A + antithrombin (each point represents growth from one aortic ring; three rings were isolated per mouse). These analyses were performed four times. F: Identical studies were done for aortic segments from WT mice treated with VEGF-A (30 ng/ $\mathrm{mL}) \pm$ vorapaxar $(10 \mathrm{ng} / \mathrm{mL})$, aortic segments from C5ar1 ${ }^{-/-}$mice treated with VEGF-A $(30 \mathrm{ng} / \mathrm{mL})$, and aortic segments from Par4 ${ }^{-/-}$Par3 $^{-/-}$and Par1 ${ }^{-/-}$mice treated with VEGF-A $(30 \mathrm{ng} / \mathrm{mL})$. These studies were performed three times. G: Diagram of C5ar1-protease-activated receptor (PAR) 4 interaction at confluence versus when cells are growing. H: Diagram of PAR and C5ar1 G $\beta \gamma$ activation of PI-3K $\gamma$ and C5ar1 PI-3K $\alpha$ via transactivation to VEGF receptor 2 (VEGFR2). PAR G $\alpha$ q activation of phospholipase C (PLC) and C5ar1 Gai repression of protein kinase A (PKA) also are depicted. The proposed activation sequence is as follows: 1 , extracellular stimulus (hypoxia/thrombin); 2, thrombin cleavage of endothelial cell C5 and PAR1/4; 3, PAR1/4/C5ar1 G $\beta \gamma$ activation of PI-3Ky and phosphorylated AKT; 4, C5ar1 transactivation to VEGFR216, 5, VEGFR2 activation of PI-3K $\alpha ; 6$, C5ar1/PAR4 induced $\uparrow$ PLC and $\downarrow$ PKA; 7, PI3K-AKT-mTOR, diacylglycerol/ $\mathrm{IP}_{3}$, and STAT3 signaling, and 8, amplified C5ar1/PAR4/VEGFR2 signaling. ${ }^{16} n=2(\mathrm{E}) .{ }^{\star} P<0.05,{ }^{* *} P<0.01$, and ${ }^{* * * P}<0.001$.

repress phosphatase and tensin homolog (PTEN) restraint of PIP3-dependent AKT activation, and PI-3K $\alpha$ (known to be VEGFR2-activated) being mechanistically involved in augmenting PIP3 generation.
Because PI-3Kr activation occurs on membranes nearby GPCRs in contrast to PI-3K $\alpha$ activation, which typically occurs on receptor tyrosine kinases ${ }^{43}$ like VEGRF2, VEGFR2 immunoprecipitations were examined for 
associated PI-3K $\alpha$ following EC activation with the PAR1, PAR4, and C5ar1 agonists. bEnd.3 cells were incubated with TP508 (PAR1 agonist), ay-NH2 (PAR4 agonist), C5a, or VEGF-A, after which extracts of the activated cells were incubated with anti-VEGFR2 mAb. Twenty-four hours later, VEGFR2 was immunoprecipitated from each incubation mixture and immunoprecipitated proteins were eluted from the alternatively activated bEnd. 3 cells. Secondary anti-PI$3 \mathrm{~K} \gamma$ or PI-3K $\alpha$ immunoprecipitations of the eluents of the anti-VEGFR2 immunoprecipitations were prepared from each incubation culture and the secondary anti-PI-3Ky immunoprecipitations and anti-PI-3K $\alpha$ immunoprecipitations were tested for PI-3K enzymatic activity. The anti-PI-3Kr immunoprecipitations from cells activated with each of the agonists uniformly lacked VEGFR2-associated PI-3Ky activity (Figure 6E). This would be in accordance with PI-3Ky (due to its membrane localization near PIP3) not being immunoprecipitated by anti-VEGFR $2 \mathrm{mAb}$. In contrast, the anti-PI-3K $\alpha$ immunoprecipitations from cells treated with all agonists uniformly contained PI-3K $\alpha$ activity, which in all cases was abolished by the VEGFR2 antagonist SU5416. These data indicate that, in contrast to the short-term incubations, PAR1 or PAR4 signaling in ECs incubated overnight induced VEGFR2 signaling and its activation of PI-3K $\alpha$. In support of this interpretation, PI-3K $\alpha$ activation by all agonists was knocked down in cells pretreated with VEGFR2 siRNA (data not shown). More studies in long-term cultures will be needed to determine whether PAR1/4 signaling transactivates directly to VEGFR2, as the recent studies have shown for C5ar1 signaling, ${ }^{16}$ whether it transactivates indirectly via the PAR4-C5ar1 complex characterized above, or whether another mechanism is involved.

Collectively, these data argue that PAR1, PAR4, and C5ar1 signaling all participate in VEGF-A's induction of EC growth. Although further studies are needed to directly validate the functional relationships and kinetics, the data are consistent with the following hypothetical formulation. They would be consistent with C5ar1 and PAR1 (because of its higher affinity than PAR4 for thrombin) initially collaborating in activating $\mathrm{PI}-3 \mathrm{Kr}$ to repress PIP3 dephosphorylation. They support prior findings that C5ar1 directly transactivates to VEGFR2 to promote its signaling. ${ }^{16}$ They further support the concept that C5ar1 Gai signaling additionally functions to enable AKT and STAT3 activation and joint PAR4 G $\alpha$ q signaling functions to enable PLC activation. The anti-VEGFR2 immunoprecipitation data following the addition to ECs of individual ligands of each receptor argue that all coordinately participate in VEGFR2-associated activation of PI-3K $\alpha$. According to the data presented herein, $\mathrm{C} 5 \mathrm{a}$ and the PAR ligands could each induce combinatorial C5ar1 and PAR4 signaling. These results are in accordance with the vorapaxar blocking studies (Figure 3), C5ar1-PAR4 association studies (Figure 5), and the assays with PAR1 and PAR4 siRNAs (Figure 4), which show that PAR1, PAR4, and C5ar1 all collaborate in enabling VEGF-A mitotic function.
Down-Regulated C5ar1 and PAR Signaling Is Connected with Contact Inhibition

The experimental system using subconfluent ECs was chosen to model proliferating ECs (eg, ECs in the context of neo-angiogenesis or reconstitution of vasculature following blood vessel severance). In this system, VEGF-A induces joint C5ar1 and PAR1/4 signaling which is integrally interconnected with VEGF-A mitotic function. Because the current studies of subconfluent ECs differ from most studies of ECs that use confluent HUVECs to model ECs in intact blood vessels, thrombin generation and C5a production in subconfluent growing HUVECs was compared to that in confluent HUVECs. Although subconfluent HUVECs expressed coagulation factor and complement component mRNAs, the mRNA expression of both systems downregulated at confluence (Figure 7A). In accordance with this result, the production of thrombin and of C5a was robust in growing HUVECs, whereas both were repressed in confluent (contact-inhibited) HUVECs (Figure 7, B and C). These findings indicate that PAR-C5ar1 signaling operates in growing ECs and is repressed with contact inhibition.

\section{VEGF-A Induction of EC Sprouting Depends on Joint C5ar1 and PAR1-PAR4 Signaling}

To validate that joint C5ar1 and PAR signaling is required for VEGF-A induction of EC growth physiologically, we performed sprouting assays. Aortic segments from WT mice incubated in Matrigel with VEGF-A showed robust sprouting compared with those from segments treated with media alone (1.07 versus $0.42 \mathrm{~mm}^{2} ; P<0.05$ ) (Figure 7D). Addition of C5ar1-A (RA) or antithrombin to the VEGF-A treated WT segments markedly attenuated the sprouting $\left(1.07 \mathrm{~mm}^{2}\right)$ versus 0.26 and $0.28 \mathrm{~mm}^{2}(P<0.05)$ (Figure 7D). The results of multiple repeated assays are summarized in Figure 7E. The inclusion of vorapaxar with VEGF-A had a similar blunting effect (Figure 7F). Consistent with these results, aortic segments from $C 5 \mathrm{arl}^{-/-}$mice, double $P A R 3^{-1}$ ${ }^{-} P A R 4^{-/}$mice, and single $P A R 1^{-/}$mice (Figure 7F) showed some sprouting in response to VEGF-A, but less than that of VEGF-A-treated WT segments. These ex vivo data are consistent with the confocal analyses in Figure $1 \mathrm{E}$ of in vivo neo-angiogenesis in implanted Matrigel plugs showing FII, FV, FVII, and FX colocalizing in CD $31^{+}$cells. They are consistent with the multiple in vitro studies linking joint PAR1/4 and C5ar1 signaling with VEGF-A mitotic function detailed above. The data further argue that both PAR and C5ar1 signaling jointly regulate EC growth physiologically.

A diagram depicting the linkage of endogenously produced thrombin and C5a with VEGF-A mitotic function in proliferating versus contact-inhibited ECs is shown in Figure $7 \mathrm{G}$. A second diagram depicting the linkage of combinatorial Gai-G $\alpha$ q signaling by the interactive PAR4C5ar1 functional complex with joint PKC activation/ 
protein kinase A inactivation and PI-3K $/ \mathrm{PI}-3 \mathrm{~K} \alpha$ signaling associated with VEGFR2 activation is shown in Figure $7 \mathrm{H}$.

\section{Discussion}

Thrombin functions to repair injured blood vessels by generating fibrin and activating platelets that together seal separated vascular segments. ${ }^{44}$ In conjunction with this, it triggers EC proliferation that enables vascular reconstitution. ${ }^{45}$ The current view is that thrombin is solely generated in the intravascular compartment from prothrombinase components that are produced by the liver. ${ }^{46}$ Although a previous study found ${ }^{47}$ that thrombin can cleave C5a from complement component $\mathrm{C} 5$, the observation was connected with heightened plasma thrombin in disease. The studies herein provide the insight that this process operates endogenously in ECs to produce $\mathrm{C} 5 \mathrm{a}$ and plays a requisite role in VEGF-A function.

The data show that in proliferating ECs: i) both coagulation factors, specifically FX, FV, FVII, and FII (prothrombin), which give rise to thrombin, and complement components, specifically $\mathrm{C} 5$ that gives rise to $\mathrm{C} 5 \mathrm{a}$, are jointly synthesized by ECs; and ii) thrombin (ie, endogenously produced by ECs) jointly cleaves C5a from EC synthesized C5 and unmasks the tethered ligands of EC expressed PAR1 and/or PAR4, that together induce combinatorial C5ar1 and PAR4 signaling. They show that: iii) the PAR4 and C5ar1 GPCRs are directly or indirectly complexed with each other in ECs and that iv) cooperative C5ar1 and PAR signaling in ECs is integrally involved in VEGF-A mitotic function. The experiments additionally provide evidence that: v) the associated PAR4-C5ar1 complex promotes combinatorial $\mathrm{G} \propto \mathrm{i}$ and $\mathrm{G} \propto \mathrm{q}$ signaling that induces PI-3K-AKT-mTOR and STAT3 activation as well as PLC activation. Finally, they provide evidence that: vi) C5ar1, PAR4, and PAR1 signaling all induce PI-3Kr activation in short-term cultures, whereas C5ar1 signaling additionally induces PI-3K $\alpha$ activation. All, however, promote PI-3K $\alpha$ activation in long-term cultures. The proximity of C5ar1 and PAR4, in principle, could promote efficient induction of joint C5ar1 and PAR4 signaling by EC produced thrombin, dual processes needed for VEGF-A mitotic function. Taken together, the findings support a requisite role of endogenous coagulation factor synthesis in EC growth. Mechanistically, they document an interconnection of the EC synthesized coagulation factors with EC synthesized complement via EC produced thrombin and show that thrombin-induced signaling through associated C5ar1 and PAR4 plays an integral role in VEGF-A mitotic function.

As emphasized in Results, it is important to highlight the difference between the studies investigating proliferating ECs herein and those by many others examining homeostatic ECs. Most in vitro studies of ECs have used HUVEC $^{31}$ grown to confluence, such that the ECs are contact inhibited. That system is intended to model conditions that pertain in intact blood vessels. Conditions that model the reconstitution of severed vessels were achieved by titrating cell numbers such that the cultures always remained nonconfluent in the presence of added VEGF-A, helping to study effects on EC proliferation in the absence of effects of contact inhibition. The comparisons of growing versus confluent HUVEC showed that although C5ar1 and PAR signaling are robust in proliferating ECs, both are repressed in confluent ECs, raising the possibility that down-regulation of this joint signaling participates in the processes that halt cell growth in contact inhibition.

Although the synthesis/presentation of tissue factor by ECs has been documented in many past studies, ${ }^{48,49}$ its function uniformly has been connected solely with intravascular coagulation. A contemporaneous study by the Moake group ${ }^{50}$ detected FVII, FIX, and FX as well as FII in confluent cultures of HUVECs and other ECs subjected to the serum-free conditions and noted that EC-produced FX could be activated without adding plasma factors. The findings in that system likewise were interpreted solely in the context of coagulation. Other prior studies ${ }^{51-53}$ have reported EC production of factor $\mathrm{B}$ and factor $\mathrm{H}$ and coagulation factors FX and FVII, and similarly interpreted the findings in the context of intravascular complement activation and coagulation. The findings herein differ from these past findings in that they document the endogenous production by ECs of the full array of prothrombinase components, leading to the intracellular production of thrombin in ECs. This process is mechanistically interconnected with VEGF-A mitotic function rather than with coagulation.

The finding herein that thrombin is produced intracellularly is supported by the intracellular fluorescence-activated cell sorting analyses of thrombin protein, and the confocal localization of FII in the bodies of ECs growing in vivo in Matrigel. It addition, it is supported by the ability of VEGF-A stimulated (primary) HAECs to support autocrine PAR1 and PAR4 signaling in serum-free cultures, the abrogation of EC growth in serum-starved cultures by PAR inhibitors, and the findings that ECs produce all prothrombinase components that generate thrombin. Disruption of EC growth by siRNA knockdowns of PAR1 and PAR4 in serum-free media provided direct confirmation of the involvement of this signaling in EC growth. Our findings that the locally produced thrombin triggers joint C5ar1 and PAR signaling and that this cooperative signaling is needed for VEGF-A function thus tie EC produced coagulation proteins to an intracellular signaling system that plays an important role in EC growth. Although this process is distinct from coagulation per se, EC proliferation is an essential process in vascular repair. Because PAR1, PAR4, ${ }^{54,55}$ C5ar1, ${ }^{56,57}$ and VEGFR2 undergo recycling between the cell surface and endosomes intracellularly, more studies will be needed to determine precisely how Angiomax and antithrombin exert their blocking effects on VEGFR2 function. More studies also will 
be needed to characterize the thrombin-mediated C5 cleavage process and the joint C5ar1 and PAR4 signaling processes spatially and structurally.

BRET, co-immunoprecipitation analyses, and confocal microscopy all indicated that PAR4 and C5ar1 are intimately associated with each other (within $10 \mathrm{~nm}$ ). The BRET studies did not detect proximity of PAR1 with C5ar1. However, the current findings that PAR1 antagonism (vorapaxar) inhibited EC proliferation, and that PAR1 agonists (TFLLRN or TP508) augmented EC proliferation, all implicated PAR1 signaling in VEGF-A function. The findings that PAR1 knockdown abolished VEGF-A induction of EC growth in serum-free media and that PAR1 genetic deficiency blunted sprouting further support this. Although the data for TP508 are controversial because a previous study indicated that TP508 activates ECs via binding to $\alpha \mathrm{v} \beta 3$ integrin, ${ }^{58}$ the combined data herein implicate TP508 in impacting PAR1 signaling. One possibility is that PAR1, which has high affinity for thrombin, is close to the PAR4-C5ar1 complex, allowing the tethered ligand of PAR1 to deliver thrombin to PAR4, similar to the reported cooperativity of murine PAR3 delivering thrombin to PAR4. ${ }^{4}$ Although possible, it is unlikely that the tethered ligand of PAR1 activates PAR4 because the sequences are different. A second possibility is that PAR1 and PAR4-C5ar1 signaling converge downstream. A precedent exists for the cooperativity of PAR1 signaling with PAR4 signaling in several systems. ${ }^{2}$ Because of differences in the extracellular regions of PAR1 and PAR4 and the higher affinity of PAR1 for thrombin, the tethered ligand of PAR4 is much less efficiently cleaved by thrombin. ${ }^{3}$ However, cooperation of PAR1 and PAR4 improves thrombin activation of PAR4. ${ }^{4}$ Functionally important, thrombin characteristically elicits a short burst of PAR1 signaling that is followed by a more prolonged expanse of PAR4 signaling. ${ }^{59}$

The finding that C5ar1 and PAR4 are associated with each other could account for past reports that C5ar1 GPCR signaling, although usually being Gi coupled (pertussis toxin sensitive) and adenylyl cyclase repressive, can also activate PLC. Some studies have attributed the PLC activation to the $\beta \gamma$ subunit of the $\mathrm{C} 5 \mathrm{ar}^{35,60} \mathrm{G}$ protein, whereas other studies ${ }^{37}$ have attributed it to alternative $\mathrm{G} \alpha \mathrm{q}$ coupling. In the same vein, some studies have reported that PAR4, although generally being $\mathrm{G} \alpha \mathrm{q}$ coupled, sometimes can be $\mathrm{G} \alpha \mathrm{i}$ coupled. ${ }^{61}$ Studies in platelets ${ }^{61}$ have found that PAR4 can couple the purinergic receptor P2Y12 that conveys G $\alpha$ i signaling. The current findings that C5ar1 is associated with PAR4 in ECs and that C5ar1 antagonism blocks thrombin suppression of protein kinase A, activation of AKT, and VEGFR2 signaling support the concept that in ECs the C5ar1-PAR4 complex could account for G $\alpha$ q coupling of C5ar1 and Gai coupling of PAR4. More studies will be needed to definitively characterize the interactions in ECs versus platelets of PAR4 with C5ar1 or with P2Y12.

Whether EC thrombin generation and intravascular thrombin generation are entirely separate processes or whether they function together remains to be determined. A corollary of this distinction is whether EC produced thrombin contributes to intravascular coagulation and intravascularly produced thrombin contributes to VEGF-A induction of EC growth. Our prior studies of immune cell activation using bone marrow chimeras consisting of wildtype bone marrow in complement-deficient recipients and vice versa ${ }^{62,63}$ showed that immune cell produced and (liver-produced) systemic complement function independently of each other in separate compartments. These results underline the functional importance of distinguishing between autocrine and paracrine receptor tyrosine kinase, PAR, and C5ar1 signaling loops operating to promote EC growth. The current data will provide a framework for more definitively unraveling the respective involvement of systemic versus EC produced thrombin in EC growth.

In conclusion, the data herein shed light on several past observations. First and foremost, endothelium has the means to synthesize endogenous complement and coagulation proteins that function to promote cell growth and angiogenesis. Recognizing this has important consequences is essential because blockade of both thrombin and C5ar1 is needed to reduce inflammation and brain edema following intracerebral hemorrhage. ${ }^{64}$ Also, the PAR and C5ar1 receptor pathways are both involved in the mobilization of hematopoietic stem/ progenitor cells, ${ }^{65}$ the inflammatory response that follows traumatic lung injury, ${ }^{66}$ and the expression of P-selectin by ECs. ${ }^{67}$ Findings by others that disrupting PAR signaling in ECs induces apoptosis ${ }^{68}$ are consistent with our findings in immune cells that disrupting C3ar1/C5ar1 signaling similarly is pro-apoptotic. ${ }^{14}$ More studies will be needed to determine whether the PAR1, C5ar1, and PAR4 autocrine signaling loops in ECs described herein regulate growth in other cell types.

\section{Acknowledgments}

We thank Micah Harland (data), Patricia Conrad (confocal), Richard Lee (imaging), Melissa DiBlasi and Victoria Turnbill (graphics), Dawn Smith (cell culture), Kathryn Franke (mice), Maria de la Fuente (bioluminescence resonance energy transfer), Alona Merkulova (angiogenesis), and I. Pikuleva (the Ophthalmology Core) for their help.

\section{Author Contributions}

D.C., M.G.S., D.C., S.S., F.A., and W.H. performed the experiments; M.G.S. analyzed the data; A.H.S. guided coagulation time and sprouting studies; M.N. guided bioluminescence resonance energy transfer analyses and protease-activated receptor studies; and M.E.M. designed and conceived the project. M.E.M. wrote the manuscript, and M.G.S., M.N., and A.H.S. edited all versions of the manuscript. 


\section{Supplemental Data}

Supplemental material for this article can be found at http://doi.org/10.1016/j.ajpath.2021.09.011.

\section{References}

1. Leibundgut G, Lee JH, Strauss BH, Segev A, Tsimikas S: Acute and long-term effect of percutaneous coronary intervention on seriallymeasured oxidative, inflammatory, and coagulation biomarkers in patients with stable angina. J Thromb Thrombolysis 2016, 41: $569-580$

2. Arachiche A, Mumaw MM, de la Fuente M, Nieman MT: Proteaseactivated receptor 1 (PAR1) and PAR4 heterodimers are required for PAR1-enhanced cleavage of PAR4 by alpha-thrombin. J Biol Chem 2013, 288:32553-32562

3. Lin H, Liu AP, Smith TH, Trejo J: Cofactoring and dimerization of proteinase-activated receptors. Pharmacol Rev 2013, 65:1198-1213

4. Nakanishi-Matsui M, Zheng YW, Sulciner DJ, Weiss EJ, Ludeman MJ, Coughlin SR: PAR3 is a cofactor for PAR4 activation by thrombin. Nature 2000, 404:609-613

5. Rezaie AR: Protease-activated receptor signalling by coagulation proteases in endothelial cells. Thromb Haemostasis 2014, 112:876-882

6. Duvernay MT, Temple KJ, Maeng JG, Blobaum AL, Stauffer SR, Lindsley CW, Hamm HE: Contributions of protease-activated receptors PAR1 and PAR4 to thrombin-induced GPIIbIIIa activation in human platelets. Mol Pharmacol 2017, 91:39-47

7. Zhao P, Metcalf M, Bunnett NW: Biased signaling of proteaseactivated receptors. Front Endocrinol 2014, 5:67

8. Jagels MA, Travis J, Potempa J, Pike R, Hugli TE: Proteolytic inactivation of the leukocyte C5a receptor by proteinases derived from Porphyromonas gingivalis. Infect Immunity 1996, 64: 1984-1991

9. Proctor LM, Arumugam TV, Shiels I, Reid RC, Fairlie DP, Taylor SM: Comparative anti-inflammatory activities of antagonists to $\mathrm{C} 3 \mathrm{a}$ and $\mathrm{C} 5 \mathrm{a}$ receptors in a rat model of intestinal ischaemia/reperfusion injury. Br J Pharmacol 2004, 142:756-764

10. Gerard C, Gerard NP: C5A anaphylatoxin and its seven transmembranesegment receptor. Annu Rev Immunol 1994, 12:775-808

11. Paiano J, Harland M, Strainic MG, Nedrud J, Hussain W, Medof ME: Follicular B2 cell activation and class switch recombination depend on autocrine C3ar1/C5ar1 signaling in B2 cells. J Immunol 2019, 203:379-388

12. Strainic MG, Shevach EM, An F, Lin F, Medof ME: Absence of signaling into $\mathrm{CD} 4(+)$ cells via $\mathrm{C} 3 \mathrm{aR}$ and $\mathrm{C} 5 \mathrm{aR}$ enables autoinductive TGF-beta1 signaling and induction of Foxp3(+) regulatory T cells. Nat Immunol 2013, 14:162-171

13. Lalli PN, Strainic MG, Yang M, Lin F, Medof ME, Heeger PS: Locally produced C5a binds to $\mathrm{T}$ cell-expressed C5aR to enhance effector T-cell expansion by limiting antigen-induced apoptosis. Blood 2008, 112:1759-1766

14. Strainic MG, Liu J, Huang D, An F, Lalli PN, Muqim N, Shapiro VS, Dubyak GR, Heeger PS, Medof ME: Locally produced complement fragments $\mathrm{C} 5 \mathrm{a}$ and $\mathrm{C} 3 \mathrm{a}$ provide both costimulatory and survival signals to naive CD4+ T cells. Immunity 2008, 28:425-435

15. O'Barr SA, Caguioa J, Gruol D, Perkins G, Ember JA, Hugli T, Cooper NR: Neuronal expression of a functional receptor for the C5a complement activation fragment. J Immunol 2001, 166:4154-4162

16. Hwang MS, Strainic MG, Pohlmann E, Kim H, Pluskota E, RamirezBergeron DL, Plow EF, Medof ME: VEGFR2 survival and mitotic signaling depends on joint activation of associated C3ar1/C5ar1 and IL-6R-gp130. J Cell Sci 2019, 132:jes219352

17. Huber-Lang M, Sarma JV, Zetoune FS, Rittirsch D, Neff TA, McGuire SR, Lambris JD, Warner RL, Flierl MA, Hoesel LM, Gebhard F, Younger JG, Drouin SM, Wetsel RA, Ward PA:
Generation of $\mathrm{C} 5 \mathrm{a}$ in the absence of $\mathrm{C} 3$ : a new complement activation pathway. Nat Med 2006, 12:682-687

18. Strainic MG, Liu J, An F, Bailey E, Esposito A, Hamann J, Heeger PS, Medof ME: CD55 is essential for CD103(+) dendritic cell tolerogenic responses that protect against autoimmunity. Am J Pathol 2019, 189:1386-1401

19. Forbes GL, Merkulova A, Pinheiro A, Lee J, Zeng P, Abdalian S, Walker AY, Wnek GE, Schmaier AH: Poly (acrylic acid) (PAA) is a contact system activator with properties to stop hemorrhage. Thromb Res 2020, 193:142-145

20. Schmaier AH: A novel antithrombotic mechanism mediated by the receptors of the kallikrein/kinin and renin-angiotensin systems. Front Med (Lausanne) 2016, 3:61

21. Stavrou EX, Fang C, Merkulova A, Alhalabi O, Grobe N, Antoniak S, Mackman N, Schmaier AH: Reduced thrombosis in Klkb1-/- mice is mediated by increased Mas receptor, prostacyclin, Sirt1, and KLF4 and decreased tissue factor. Blood 2015, 125 710-719

22. Gupta S, Konradt C, Corken A, Ware J, Nieswandt B, Di Paola J, Yu M, Wang D, Nieman MT, Whiteheart SW, Brass LF: Hemostasis vs. homeostasis: platelets are essential for preserving vascular barrier function in the absence of injury or inflammation. Proc Natl Acad Sci U S A 2020, 117:24316-24325

23. Nieman MT: RAPid signaling in platelets. Blood 2018, 132 $1864-1865$

24. Amthauer R, Kodukula K, Brink L, Udenfriend S: Phosphatidylinositol-glycan (PI-G)-anchored membrane proteins: requirement of ATP and GTP for translation-independent $\mathrm{COOH}$-terminal processing. Proc Natl Acad Sci U S A 1992, 89:6124-6128

25. de la Fuente M, Noble DN, Verma S, Nieman MT: Mapping human protease-activated receptor 4 (PAR4) homodimer interface to transmembrane helix 4. J Biol Chem 2012, 287:10414-10423

26. Larusch GA, Merkulova A, Mahdi F, Shariat-Madar Z, Sitrin RG, Cines DB, Schmaier AH: Domain 2 of uPAR regulates single-chain urokinase-mediated angiogenesis through beta1-integrin and VEGFR2. Am J Physiol Heart Circ Physiol 2013, 305:H305-H320

27. Sakuma M, Morooka T, Wang Y, Shi C, Croce K, Gao H, Strainic M, Medof ME, Simon DI: The intrinsic complement regulator decayaccelerating factor modulates the biological response to vascular injury. Arterioscler Thromb Vasc Biol 2010, 30:1196-1202

28. Darmoul D, Gratio V, Devaud H, Lehy T, Laburthe M: Aberrant expression and activation of the thrombin receptor protease-activated receptor-1 induces cell proliferation and motility in human colon cancer cells. Am J Pathol 2003, 162:1503-1513

29. Moon JY, Franchi F, Rollini F, Angiolillo DJ: Role for thrombin receptor antagonism with vorapaxar in secondary prevention of atherothrombotic events: from bench to bedside. J Cardiovasc Pharmacol Ther 2018, 23:23-37

30. Yang J, Xu K, Seiffert D: Challenges and promises of developing thrombin receptor antagonists. Recent Patents Cardiovasc Drug Discov 2010, 5:162-170

31. Waitkus MS, Chandrasekharan UM, Willard B, Haque SJ, DiCorleto PE: STAT3-mediated coincidence detection regulates noncanonical immediate early gene induction. J Biol Chem 2013, 288:11988-12003

32. Moschonas IC, Kellici TF, Mavromoustakos T, Stathopoulos P, Tsikaris V, Magafa V, Tzakos AG, Tselepis AD: Molecular requirements involving the human platelet protease-activated receptor-4 mechanism of activation by peptide analogues of its tethered-ligand. Platelets 2017, 28:812-821

33. Strainic MG, Pohlmann E, Valley CC, Sammeta A, Hussain W, Lidke DS, Medof ME: RTK signaling requires C3ar1/C5ar1 and IL6R joint signaling to repress dominant PTEN, SOCS1/3 and PHLPP restraint. FASEB J 2020, 34:2105-2125

34. Khan A, Li D, Ibrahim S, Smyth E, Woulfe DS: The physical association of the P2Y12 receptor with PAR4 regulates arrestinmediated Akt activation. Mol Pharmacol 2014, 86:1-11 
35. Jiang H, Kuang Y, Wu Y, Smrcka A, Simon MI, Wu D: Pertussis toxin-sensitive activation of phospholipase $\mathrm{C}$ by the $\mathrm{C} 5 \mathrm{a}$ and fMetLeu-Phe receptors. J Biol Chem 1996, 271:13430-13434

36. Lee CH, Katz A, Simon MI: Multiple regions of $\mathrm{G}$ alpha 16 contribute to the specificity of activation by the C5a receptor. Mol Pharmacol 1995, 47:218-223

37. Buhl AM, Eisfelder BJ, Worthen GS, Johnson GL, Russell M: Selective coupling of the human anaphylatoxin C5a receptor and alpha 16 in human kidney 293 cells. FEBS Lett 1993, 323: $132-134$

38. Amatruda TT 3rd, Gerard NP, Gerard C, Simon MI: Specific interactions of chemoattractant factor receptors with G-proteins. J Biol Chem 1993, 268:10139-10144

39. Simons M, Gordon E, Claesson-Welsh L: Mechanisms and regulation of endothelial VEGF receptor signalling. Nat Rev Mol Cell Biol 2016, 17:611-625

40. Rahman A, True AL, Anwar KN, Ye RD, Voyno-Yasenetskaya TA, Malik AB: Galpha(q) and Gbetagamma regulate PAR-1 signaling of thrombin-induced NF-kappaB activation and ICAM-1 transcription in endothelial cells. Circ Res 2002, 91:398-405

41. Xie Y, Abel PW, Kirui JK, Deng C, Sharma P, Wolff DW, Toews ML, Tu Y: Identification of upregulated phosphoinositide 3-kinase gamma as a target to suppress breast cancer cell migration and invasion. Biochem Pharmacol 2013, 85:1454-1462

42. Stein PH, Fraser JD, Weiss A: The cytoplasmic domain of CD28 is both necessary and sufficient for costimulation of interleukin-2 secretion and association with phosphatidylinositol 3'-kinase. Mol Cell Biol 1994, 14:3392-3402

43. Alberts B, Johnson A, Lewis J, Morgan D, Raff MC, Roberts K, Walter P, Wilson J, Hunt T: Molecular Biology of the Cell. ed 6. New York, NY, Garland Science, 2014

44. Brummel KE, Paradis SG, Butenas S, Mann KG: Thrombin functions during tissue factor-induced blood coagulation. Blood 2002, 100: $148-152$

45. Dupuy E, Habib A, Lebret M, Yang R, Levy-Toledano S, Tobelem G: Thrombin induces angiogenesis and vascular endothelial growth factor expression in human endothelial cells: possible relevance to HIF-1alpha. J Thromb Haemost 2003, 1:1096-1102

46. Sullivan BP, Kopec AK, Joshi N, Cline H, Brown JA, Bishop SC, Kassel KM, Rockwell C, Mackman N, Luyendyk JP: Hepatocyte tissue factor activates the coagulation cascade in mice. Blood 2013, $121: 1868-1874$

47. Oikonomopoulou K, Ricklin D, Ward PA, Lambris JD: Interactions between coagulation and complement-their role in inflammation. Semin Immunopath 2012, 34:151-165

48. Graf C, Ruf W: Tissue factor as a mediator of coagulation and signaling in cancer and chronic inflammation. Thromb Res 2018, 164(Suppl 1):S143-S147

49. Yu Y, Boing AN, Hau CM, Hajji N, Ruf W, Sturk A, Nieuwland R: Tissue factor coagulant activity is regulated by the plasma membrane microenvironment. Thromb Haemost 2018, 118:990-1000

50. Cohen CT, Turner NA, Moake JL: Production and control of coagulation proteins for factor $\mathrm{X}$ activation in human endothelial cells and fibroblasts. Sci Rep 2020, 10:2005

51. Ku SK, Bae JS: Antithrombotic activities of wogonin and wogonoside via inhibiting platelet aggregation. Fitoterapia 2014, 98:27-35

52. Lee W, Ku SK, Bae JS: Factor Xa inhibits HMGB1-induced septic responses in human umbilical vein endothelial cells and in mice. Thromb Haemost 2014, 112:757-769

53. Dauchel H, Julen N, Lemercier C, Daveau M, Ozanne D, Fontaine M, Ripoche J: Expression of complement alternative pathway proteins by endothelial cells: differential regulation by interleukin 1 and glucocorticoids. Eur J Immunol 1990, 20:1669-1675
54. Smith TH, Coronel LJ, Li JG, Dores MR, Nieman MT, Trejo J: Protease-activated receptor-4 signaling and trafficking is regulated by the clathrin adaptor protein complex-2 independent of beta-arrestins. J Biol Chem 2016, 291:18453-18464

55. Grimsey NJ, Coronel LJ, Cordova IC, Trejo J: Recycling and endosomal sorting of protease-activated receptor-1 is distinctly regulated by Rab11A and Rab11B proteins. J Biol Chem 2016, 291: 2223-2236

56. Arbore G, West EE, Spolski R, Robertson AAB, Klos A, Rheinheimer C, Dutow P, Woodruff TM, Yu ZX, O'Neill LA, Coll RC, Sher A, Leonard WJ, Kohl J, Monk P, Cooper MA, Arno M, Afzali B, Lachmann HJ, Cope AP, Mayer-Barber KD, Kemper C: T helper 1 immunity requires complement-driven NLRP3 inflammasome activity in $\mathrm{CD} 4(+) \mathrm{T}$ cells. Science 2016, 352: $\operatorname{aad} 1210$

57. Liszewski MK, Kolev M, Le Friec G, Leung M, Bertram PG, Fara AF, Subias M, Pickering MC, Drouet C, Meri S, Arstila TP, Pekkarinen PT, Ma M, Cope A, Reinheckel T, Rodriguez de Cordoba S, Afzali B, Atkinson JP, Kemper C: Intracellular complement activation sustains $\mathrm{T}$ cell homeostasis and mediates effector differentiation. Immunity 2013, 39:1143-1157

58. Tsopanoglou NE, Papaconstantinou ME, Flordellis CS, Maragoudakis ME: On the mode of action of thrombin-induced angiogenesis: thrombin peptide, TP508, mediates effects in endothelial cells via alphavbeta3 integrin. Thromb Haemostasis 2004, 92:846-857

59. Canto I, Soh UJ, Trejo J: Allosteric modulation of protease-activated receptor signaling. Mini Rev Med Chem 2012, 12:804-811

60. Roach TI, Rebres RA, Fraser ID, Decamp DL, Lin KM, Sternweis PC, Simon MI, Seaman WE: Signaling and cross-talk by C5a and UDP in macrophages selectively use PLCbeta3 to regulate intracellular free calcium. J Biol Chem 2008, 283:17351-17361

61. Thibeault PE, LeSarge JC, Arends D, Fernandes M, Chidiac P, Stathopulos PB, Luyt LG, Ramachandran R: Molecular basis for activation and biased signaling at the thrombin-activated GPCR proteinase activated receptor-4 (PAR4). J Biol Chem 2020, 295: $2520-2540$

62. Sheen JH, Strainic MG, Liu J, Zhang W, Yi Z, Medof ME, Heeger PS: TLR-induced murine dendritic cell (DC) activation requires DC-intrinsic complement. J Immunol 2017, 199:278-291

63. Kwan WH, Hashimoto D, Paz-Artal E, Ostrow K, Greter M, Raedler H, Medof ME, Merad M, Heeger PS: Antigen-presenting cell-derived complement modulates graft-versus-host disease. J Clin Invest 2012, 122:2234-2238

64. Li G, Fan RM, Chen JL, Wang CM, Zeng YC, Han C, Jiao S, Xia XP, Chen W, Yao ST: Neuroprotective effects of argatroban and C5a receptor antagonist (PMX53) following intracerebral haemorrhage. Clin Exp Immunol 2014, 175:285-295

65. Hoth JJ, Wells JD, Jones SE, Yoza BK, McCall CE: Complement mediates a primed inflammatory response after traumatic lung injury. J Trauma Acute Care Surg 2014, 76:601-608. discussion 608-609

66. Borkowska S, Suszynska M, Mierzejewska K, Ismail A, Budkowska M, Salata D, Dolegowska B, Kucia M, Ratajczak J, Ratajczak MZ: Novel evidence that crosstalk between the complement, coagulation and fibrinolysis proteolytic cascades is involved in mobilization of hematopoietic stem/progenitor cells (HSPCs). Leukemia 2014, 28:2148-2154

67. Foreman KE, Vaporciyan AA, Bonish BK, Jones ML, Johnson KJ, Glovsky MM, Eddy SM, Ward PA: C5a-induced expression of P-selectin in endothelial cells. J Clin Invest 1994, 94:1147-1155

68. Zhu Z, Reiser G: PAR-1 activation rescues astrocytes through the $\mathrm{PI} 3 \mathrm{~K} / \mathrm{Akt}$ signaling pathway from chemically induced apoptosis that is exacerbated by gene silencing of beta-arrestin 1. Neurochem Int 2014, 67:46-56 